\title{
2 Meaning: Primary, Pragmatic, and Others
}

This chapter serves two purposes: firstly, it introduces the idea that meaning statements-i.e. statements of the form " $x$ means $y$ "-can be conceived as descriptions. Descriptions that are such that, relative to a given background theory, they illuminate the role a specific word plays in a particular language. The discussion of this idea is an excellent backdrop against which I can give an overview of established theories of meaning. The basic idea of this overview is not to argue for a particular position, but rather to get to grips with the massive variety of possible approaches in the field of semantics. Secondly, it gives a rough overview on construction grammar ( $\mathrm{CxG}$, henceforth). In particular, I will introduce those aspects of $\mathrm{CxG}$ that are especially relevant to philosophical theories of meaning (rather than for semantics per se). That is to say, my main emphasis here lies on (i) showing that $\mathrm{CxG}$ fosters the decline of a sharp boundary between semantics and pragmatics and on (ii) showing how $\mathrm{CxG}$ fits with modern theories of language acquisition. These two points are particularly relevant as they lend support to a broadly usage-based approach to meaning, despite the prevailing success of formal theories in philosophical semantics.

Accordingly, the chapter is divided into two sections. In the first section (2.1), I will be dealing with meaning statements in general. Besides giving an overview of semantic theories, in this section I propose to take a liberal stance toward meaning statements; a topic that I take up again in the third part of this book. Also, I give a first overview on compositionality, because compositionality will become quite important in later chapters in the discussion of truth-conditional semantics. In the second section (2.2), I give an overview on $\mathrm{CxG}$. In this section, I also briefly introduce the notion of multimodality, as compositionality is an aspect of language that $\mathrm{CxG}$ seems particularly well suited to cope with. 


\subsection{Meaning Statements are Descriptions}

All sorts of theories get labelled 'theories of meaning' or 'semantic theory'. The purpose of this section is to give an overview on how varied the field of semantics actually is. By doing this, I propose to conceive of all semantic statements-statements of the form " $x$ means $y$ "-as descriptions. More precisely, I shall argue that semantic statements describe that particular set of knowledge concerning a particular linguistic item that a competent natural-language user associates with this item. This indeed quite general characterisation of "meaning" will serve as something like an 'outer boundary', if you like. That is to say, all actual semantic statements are, in fact, descriptions. ${ }^{1}$ But something else must be added to a proper characterisation of "meaning" in order to sort out inappropriate descriptions. Framing such an 'inner boundary', then, will be the task of later chapters.

1 Prima facie, this seems to be in stark contrast to what people like Lewis think semantics does actually (Lewis 1970, e.g. p. 18). Although I would tend to think that there is a fundamental difference between treating 'meanings' as entities and treating them as something else, I would argue that the claim that all semantic statements are descriptions is well justified, despite that difference. The reason is that-see 6.2-I distinguish between semantic descriptions and their respective justifications. In that sense, even Lewis, who thinks that 'genuinely semantic relations [... are] relations between symbols and the world of non-symbols' and that semantics (in his sense of the term) is a 'description of possible languages or grammars as abstract semantic systems whereby symbols are associated with aspects of the world' $(1970,19)$, effectively offers some sort of description when it comes to semantic statements. No matter what semantic statements describe (use, reference relations, or something else) and no matter how they do it (specifically for individual terms, or rather generically for types of terms), they all, at least, describe what 'meaning' is, from their perspective. For Lewis, the meanings of names can generically described thus:

[A] meaning for a name is something that determines what thing, if any, the name names in various possible states of affair, at various times, and so on. [...A]n appropriate intension for a name is any function from indices to things $[\ldots] .(1970,23)$

Accordingly, in line with that view, what I call 'constitutive basis' further below is not use, but rather a certain symbol-world relation. And that is what legitimises a certain semantic statement, or not. Be that as it may, the differences between different semantics concern only their justificatory bases, not their way of describing relationships between certain linguistic units (e.g. words) and some other things (e.g. things). 
In line with established practice in linguistics and philosophy, I need to note right at the beginning that in the following I will presuppose the fundamental distinction between literal and non-literal meaning. Thus, for a large part of this book, I will presuppose that there is some theoretically relevant difference between, say, "There is no milk in the fridge" meaning 'that there is no milk in the fridge' and 'that there is no more milk to drink available in the fridge'. Although, eventually, one of the main aims of this book is to show that this strict distinction is unjustified, it makes sense to take it for granted in the following overview. Because, firstly, it is a common assumption in all relevant semantic theories anyway; accordingly, presenting an overview in line with the distinction seems required. And, secondly, literal meaning is theoretically relevant in several respects (e.g. in explaining metaphors); so there is independent reason to equip the theory framework that I will present in the course of this book with a theoretic notion that is capable of explaining non-literality.

As just indicated, one major position to be defended in the chapters below is that it is not entirely unproblematic to assume that semantics should be dealing solely with literal meaning, i.e. context-free, formally specifiable meaning. Rather, semantics should be viewed as an enterprise that involves far more elements from (traditional) pragmatics than usually assumed. This view is motivated mainly by some recent developments in linguistics, in particular in grammar theory $(\mathrm{CxG})$ and language evolution (Tomasello's programme) ${ }^{2}$. Both will be explained at length later on. The notion "literal meaning" has quite a few cognates in the literature, among them "lexical", "stable", "first", "semantic", "invariant", and "conventional". The conceptual differences between these notions, if any, are not relevant for my present purposes though. Just to avoid confusion, I will stick to "primary meaning" in the following. In a first step, I will present the way pragmatic meaning is typically conceived in the literature, i.e. in terms of reference relations. In a second step, I propose a refined definition of the

2 One of the readers of this chapter reminded me of the fact that this paradigm is not entirely uncontroversial. Yes, but what is? Moreover, what, I take it, is relatively uncontroversial is that within the last decade, Tomasello's approach to language acquisition gained significant popularity within the relevant scientific community. This should be enough of a starting point for a philosophical theory that is supposed to correspond to the developments taking place in the empirical disciplines. 
term that fits better with my demands. For reasons that will emerge later, I will dub the counterpart "pragmatic meaning" (instead of "non-literal" or "derived").

Primary meaning as a theoretical notion is essentially needed to account for a variety of important, systematic linguistic effects such as irony, slip of the tongue, etc. In this chapter, I will argue for a liberal stance on meaning in general. Note that the qualification "literal" (or its equivalent) is often omitted in the literature in otherwise unambiguous contexts, which is to say that the following remarks apply primarily to 'meaning statements' that deal specifically with primary meaning in my sense of the term. Yet, since my plan is to omit ordinary primary meaning altogether (by proposing a new definition of the term that is capable of fulfilling the task of accounting for effects such as irony, slip of the tongue, etc.), it seems natural to take one step at a time. I begin with a general overview on meaning statements; after this I then turn to issues that are particularly relevant for primary meaning.

\subsubsection{What is Meaning and What is It Good For?}

For the task at hand, I understand "meaning" provisionally as follows (further qualifications in due course): the meaning of a word is a description of what competent language users typically associate with this word, i.e. a description of how they understand the term in question. This definition only serves the purpose of motivating a great deal of examples and will be specified later on. Prototypical examples of meaning statements are lexicon entries. Lexicon entries reformulate or paraphrase, in more common terms, what a competent speaker associates with a given word. The meaning of a sentence, then, would be a description of what competent language users typically associate with this sentence, a description that is often systematically dependent on (primary) meanings of sub-sentential parts and syntactic structure. ${ }^{3}$

3 See also the sections on compositionality (2.1.3 and 5.2.3). 
I shall first clarify this definition step by step. What is a description? A description is any paraphrase of a given word (or sentence) ${ }^{4}$ that helps illuminating how a competent speaker understands this word. 'Understanding a term', in turn, means implicitly knowing how to use this term (Horwich 1998, 16-18). Descriptions are paraphrases of a given word by any person or institution that enjoys authority concerning the relevant language: for instance, lexicons, linguists, native speakers, etc. Here is an example: "church service", for example, means 'a formalized period of communal worship" ${ }^{5}$. Now assume the following: Mary asks Peter: "Peter, what is a church service?" Peter replies: "A church service is a formalised period of communal worship." Assume further that Mary understands "formalised", "period", "communal", and "worship", and the relevant syntactic structure (copula sentence). ${ }^{6}$ In the terminology that I adopt here, this amounts to saying that she implicitly knows how to use the terms (i.e. how to apply them and how they are actually used by other members of her linguistic community). Relative to these assumptions, Mary understands "church service" after having heard Peter's instructions. His description was illuminating - as, in fact, any other description would have been that would have had the same effect in Mary. In general, a description of the meaning of a given term is correct if it enables an otherwise competent speaker to know how this term is used in the respective language community. Conversely, if the latter is already known (which is the more interesting case in linguistics), a given description is correct if, and only if, it accords with this prior knowledge. In this way, meaning statements, varied as they are in practice, are all alike in that their adequacy necessarily hinges on whether they accord with prior knowledge concerning use.

4 For sake of brevity, I omit reference to sentences in the following. In many cases it will be clear in which way explanations for words can be applied, mutatis mutandis, to sentences. Whenever there are potential ambiguities, I will explicitly mention them.

5 Entry 'Church service', Wikipedia, http://en.wikipedia.org/wiki/ Church_service, accessed on: 28/02/2013.

6 Please note that the line of argument that follows takes Paul Horwich's notion of 'understanding' for granted, including his justification. This notion is controversial. In particular, people question Horwich's view on implicit knowledge (Fodor \& Lepore 2002, ch. 3, pp. 43-62). Thus, my argument hinges on the success of Horwich's. 
All this, to be sure, is about knowing-how. ${ }^{7}$ In line with Horwich's approach, I assume that when Mary learns how to use "church service", she is not (necessarily) in a position to declare what this knowledge is. She is not (necessarily) able to tell in which situations "church service" would be applicable, for instance. Rather, her knowledge, if any, consists in her ability to apply "church service" in a way that is sufficiently similar to the way other competent speakers of English would use it. Nothing over and above this ability is required in order to be justified in ascribing understanding to Mary. In other words, learning the meaning of "church service" is, in important respects, more like learning to ski (knowing-how) than learning that green is a colour (knowing-that). This is even more important when it comes to syntactic knowledge, which is typically not available to language users in such a way that they could actually declare what their (syntactic) knowledge consists in.

So far I have talked rather naïvely about someone's knowing how to apply a given term. Even if we agree that this kind of knowledge is implicit, there is still a certain degree of controversy regarding how to narrow it down any further. Following Wittgenstein's terminology, knowledge concerning the use of a term is often conceived of in terms of the relevant rules that supposedly 'guide' one's use. Again, the nature and status of rules is highly controversial. ${ }^{8}$ I bracket this issue here (and elaborate further in 3.1.2). Let me just stress that the implicit knowledge that constitutes a subject $S$ 's understanding of a word " $w$ " is just that kind of knowledge that manifests itself in specific, systematic, behavioural patterns of $S$ towards occurrences of " $w$ ".

I propose to conceive of the notion of a 'description' in a liberal manner. I said that descriptions paraphrase how a given term is used. A paraphrase, however, can only be illuminating relative to a given system. The most obvious such system is natural languages. For example, the paraphrase "a formalised period of communal worship" is illuminating relative to the system of English. Apparently, there are also many statements that can legitimately be considered proper meaning statements but which are only

\footnotetext{
For issues surrounding this notion, cf. Jung \& Newen (2010) and Stanley \& Williamson (2001).

8 See, e.g., the references in Biletzki \& Matar (2014, section 3.5).
} 
informative or illuminating relative to some other system. What makes a meaning statement illuminating (relative to a specific system) is sometimes only remotely similar to what makes natural language paraphrases illuminating.

To see this, consider grammar theory, for instance. A grammar theory such as head-driven phrase structure grammar (HPSG) consists of meaning statements, among other things. Yet, the fundamental purpose of a grammar theory is to distinguish grammatical from ungrammatical sentences. That is to say, its purpose is to determine, for any complex string of symbols, whether a specific string in a given language is grammatical relative to the formation rules provided by the theory. ${ }^{9}$ The 'meaning statements' in HPSG are, arguably, the semantic aspects of (HPSG) lexicon entries. It seems reasonable to suppose that these representations are a kind of paraphrase, because they illuminate how words are used (or are thought to be used) relative to the system of HPSG. For example, they illustrate what semantic aspect a single word contributes to the meaning of a complex expression. Hence, there is reason to define "meaning" in such a way that it is capable of covering formalisms such as HPSG. Relative to their respective systems, the representations of at least certain grammar formalisms paraphrase the meaning of a given term.

Another quite illustrative example of what a 'paraphrase' might look like is translation. Consider the two terms "breakfast" (an English word) and "Frühstück" (a German word). Both, let us suppose, mean the same. In other words, there are structural similarities between how "breakfast" is used in English, relative to the rest of English, and how "Frühstück" is used in German, relative to the rest of German. Teaching an English-speaking

9 At least, this is what is done in HPSG. Other grammar theories might be different in this respect. HPSG is a lexicon-based grammar, i.e. a grammar that 'moves' all information into the lexicon. Besides the lexicon, there is only a handful of quite general rules. The important part of lexicon entries is their syntactic information. If two entries (words, morphemes, suffixes, etc.) are combined, their respective representations are unified, which is only possible if the syntactic information is compatible (Müller 2013b, 195206). Despite the quite heavy technical machinery employed in HPSG, the basic working principle is really simple: the complex strings that emerge from unifying lexicon entries are 'grammatical'; everything else is 'ungrammatical'. Note, by the way, that the idea that lexical entries in HPSG represent primary meaning is not controversial (Sag \& Wasow 1999, 103). 
person with basic knowledge of German the meaning of "Frühstück" is possible by simply telling her that "Frühstück" translates to "breakfast". Accordingly, an instance of

"Frühstück" translates to / means "breakfast"

is a paraphrase on the view proposed here, because it is an illuminating description of how "Frühstück" is used in the community of German-speaking people. In general, it seems quite reasonable to assume that, for every meaning statement, there is a way to conceive of this statement as paraphrasing the use of a term relative to a specifiable language system (natural language; grammar theory; formal-semantic system; knowledge representation system; and so on).

The link between use and meaning statements is quite tight in everyday discourse. Of course, the function of a paraphrasing statement is to tell someone (who is otherwise competent in the relevant system) how a specific word is used relative to this system. However, the adequacy criterion for a paraphrase-be it a lexicon entry, a translation, or what have youis just the reverse. That is to say, in order to determine whether a given meaning statement is correct, we would ask someone who already is familiar with the relevant language system (including the term in question)-or better: ask several such people-if this meaning statement paraphrases the use of this specific term correctly. In order to assess a given translation, one would ask a speaker who is competent in both relevant languages whether the terms on the left-hand side and on the right-hand side are used structurally similar in their respective languages.

What does "competent" mean in the above definition? It is quite common in the philosophy of language to assume 'standard' or 'average' language users (e.g. Stalnaker 1984). They are taken to be competent in a given language such as English. Normally, the notion of a 'competent speaker' is introduced by examples. A competent average user of English, for example, knows a priori that the sentence "All bachelors are unmarried" is true qua being competent in English. (Truth follows by definition.) Note, however, that this is true only if one takes for granted that the average speaker of English is familiar with the definition of, e.g., "unmarried". What about the truth of "Local supervenience implies global supervenience"? It is true by definition, hence knowable a priori. Nevertheless, one would not as- 
sume that an average speaker knows this, for he lacks lexical knowledge of the terms in this sentence (except for "imply", maybe). The definition of a 'standard' speaker of a natural language presupposes a certain set of lexical knowledge that one would typically ascribe to such a speaker. "Unmarried" would probably be in it, "supervenience" not. For present purposes, I only need the notion of "competence", anyway. I restrict competence not to whole languages, but to words. In the Peter/Mary example, a description of "church service" along the lines of "a formalised period of communal worship" counts as a correct description iff someone who is competent in using "church service" typically associates 'formalised periods' with this word. That is, the notion of 'competence' with respect to individual words is independent from other linguistic knowledge that a speaker might (also) have. $^{10}$

What does it mean that a language user 'associates' something with a word? I suggest that associating a word with something else can more or less be equated with understanding. This is motivated as follows: a meaning statement is typically a paraphrase of how a word is used by competent speakers. Hence, if I say that someone associates 'formalised periods of communal worship' with the concept of "church service", then this amounts to the claim that, mutatis mutandis, his use of "formalised periods of communal worship" is systematically similar to that of "church service" (though not identical). This, in turn, means that the implicit knowledge associated with the use of "church service" and "formalised periods of communal worship" is systematically similar. Hence, a competent speaker may be said to understand "church service" in the sense of 'formalised periods of communal worship'. This view suggests that a certain use might be indicative of understanding, while understanding is treated as knowledge of use-a view that might sound circular to some. Against this, I can only say that I am not aware of any plausible explication of 'understanding' that would lack the assumption that understanding of a given term is implicitly

${ }^{10}$ This is true if we ignore issues surrounding holism for a moment (cf. section 3.2.2). Because, roughly put, a speaker can't be just competent in using a given word if he is not also competent in using some other words that are meaning-related (in extreme cases, all other words of the relevant language). I assume in what follows that a speaker's competence in using a particular word is reasonably clear. Incorporating holism, would unnecessarily complicate matters at this point. 
exemplified by some typical patterns of use associated with that term. I doubt that even a die-hard truth-conditional semanticist would seriously deny this.

\subsubsection{Meaning Liberalism}

If I now take for granted in the following that, for example, (i) 'formalised periods of communal worship' is a proper paraphrase of "church service"; that (ii) a paraphrase is appropriate if it helps competent language users to understand how a given word is used; and that (iii) from a pre-theoretic perspective, meaning statements describe implicit use knowledge, then, at first glance, it might seem that my conception of meaning is indeed quite narrow.

On the contrary, I propose to take a very liberal stance toward meaning statements. That is, I suggest defining "meaning" first of all in such a broad way as to include a broad variety of different cases. The idea behind this is to have a wide, pre-theoretic notion of "meaning" at hand that poses no ex-ante restrictions on genuine meaning statements. Philosophically more interesting are two further questions that can be accounted for independently, I think. One is the nature of meaning, which is the actual core of all philosophical (foundational/reductionistic) theories of meaning. The proper treatment of this issue, however, is unaffected by the acknowledgement that, essentially, all existing meaning statements are paraphrases, whose adequacy is determined relative to how well they accord with one's pre-theoretic knowledge concerning use. Another issue is the relative appropriateness of particular theories, which is just the other side of the coin. Once you 'know' the nature of meaning, you also know how to classify existing theories according to how well they fit with this conception.

Since, as I have just shown, there is an independent reason for a liberal, pre-theoretic definition of "meaning", it is the aim of the following few paragraphs to look more closely at some typical kinds of meaning statements in order to see whether they are covered by the pre-theoretic conception of meaning as 'paraphrases of implicit knowledge of use'. To this end, I shall, in particular, look at list of relevant examples that exemplify the broad range of natural-language cases that are typically discussed in 
the relevant literature in language philosophy. Such a list of paradigm examples would typically include the following:

Translation How is meaning conveyed by translations?

Reference What about meaning statements in terms of reference?

Discourse How do we cope with discourse representations?

Lexica Is a lexical entry a meaning description?

Formalisms Can formal representations be conceived of as paraphrases?

Trivialism If "dog" meant $\mathrm{DOG}^{11}$, what would this mean?

Ostensive definitions Can meanings be 'paraphrased' by ostensive definitions?

Translations: A typical example of a meaning statement is when someone translates a word from one natural language into another. For example, one might say: "Schnee" means 'snow' in German, or, alternatively, "Schnee" is the German equivalent to our (English) "snow" (like in a dictionary). Similarly, we typically 'translate' words or sentences from natural languages to metalanguages, as in the notorious "'Schnee ist weiß' is true if and only if snow is white". ${ }^{12}$ Translations are the most straightforward examples of paraphrases, as a 'normal' paraphrase is nothing but a 'translation' within

${ }^{11}$ Horwich (1998) uses capitalised words to denote meanings (see below).

${ }^{12}$ Note that for the present argument it does not matter whether truth conditions are sufficient descriptions of meaning. Even a use theorist might allow for T-sentences (see 4.1.3), i.e. sentences that specify at a meta-level the truth conditions of a given objectlevel sentence-as long as these conditions are not identified with meaning. The obvious reason is this: the meaning, describable in terms of use, of our own language (English/the metalanguage) is known and, in principle, explicable. It is quite a good heuristic method to assume that people with otherwise similar environment and similar psychological make-up to ourselves will use their sentence "Schnee ist weiß" in a structurally similar manner to the way we use "Snow is white", given that the truth conditions of these sentences are identical. In this sense, T-sentences are actually nothing over and above ordinary translations. Given the tight link between T-sentences and the criteria for their respective adequacy (which is use, at the end of the day), there is nothing special about usage-based theories that assign truth conditions to sentences and referential relations to terms (cf. Horwich 1998, ch. 4). 
a given language. It paraphrases, in terms known to the addressee, the meaning of a given term that might be unknown to that addressee. Analogously, translations also presuppose that certain terms, namely that ones in which the translation is couched, are known to the addressee, whereas other terms, namely those that get translated, do not necessarily need to be thus known. For example, someone who says that "Schnee" means 'snow' in German presupposes that the addressee knows the meaning of "snow"; otherwise the relevant T-sentence would be incomprehensible to the addressee. And what he says, actually, is that the use of "Schnee" in German is structurally similar to the use of "snow" in English (plus minus the inaccuracy of our dictionaries). I emphasise 'structurally', because it is a similarity relative to German, of course.

If "Schnee" and "snow" have equivalent meaning, the similarity between the two in terms of use is just this: considering the correspondences between related pairs of words in German and English-e.g. the fact that "weiß" means 'white'-the tendency of competent speakers of German to apply "Schnee" and the tendency of competent speakers of English to apply "snow" is absolutely alike (all else being equal). From this point of view, translations are a paradigm example of meaning statement (i.e. paraphrases), as they are shorthand descriptions of how a given word or sentence would be used in the relevant target language. Trivially, 'intra-language translations' as well as proper translations between two languages are equally as informative or illuminating for an addressee as she is able to understand that bit of information to which the paraphrase recurs. For example, the information that "Schnee" means 'snow' in German is only informative for you, the reader, to the extent that you are competent in German (and English).

Reference: Another relevant example is reference, such as reference of proper names. It is undeniable that there must be some connection between reference and meaning. Some people in the history of philosophy of language even go as far as to say that reference is meaning (e.g. Mill 1916)-an idea that lives forth in truth-conditional semantics and neo-Davidsonian approaches. Others (e.g. Carnap 1956) add additional layers (intensions) in order to determine reference. These people stick to the main idea of identifying meaning with reference, because the main purpose of the intermediate level is solely to fix reference. This is an approach to semantics 
that continues to be developed in all strands of linguistics and philosophy related to possible worlds semantics (now classical milestones include the works of Lewis (1970, 1975, 1980), Kaplan (especially his 1989), Montague (1974), ${ }^{13}$ and Partee (e.g. 1976, 1977)). Among more recent proponents of frameworks directly working with, or being inspired by possible worlds are Emma Borg (2004b, 2012a, 2012b), Herman Cappelen (e.g. 2004), or William Lycan (2010). ${ }^{14}$ Still others-i.e. all those not belonging to the first two camps-are sceptical about the identification of meaning and reference (plus truth-conditional functions) but argue that it is an essential element of any serious semantic theory. At any rate, meaning and reference seem to be tightly linked.

Further evidence for a close link between reference and meaning comes from everyday discourse: very often, one can hear people saying things like “Water' means $\mathrm{H}_{2} \mathrm{O}$ ” or "“Today' means 31 January”. Professional philosophers would reformulate this and say instead: "Water' refers to $\mathrm{H}_{2} \mathrm{O}$ " and "Today' refers to the 31 January" (on 31 January). In fact, this way of reformulating it is the only way to 'make sense' of these utterances. People clearly can't mean that "today" means the same as "on 31 January", because the referents of both terms are only alike on 31st of January. Similarly for "water": it only refers to $\mathrm{H}_{2} \mathrm{O}$ in ' $\mathrm{H}_{2} \mathrm{O}$ worlds' (an assumption that is commonplace in philosophy since Putnam 1975 and Burge 1979; cf. also Chalmers 2006). The close link that holds between reference and meaning

\footnotetext{
${ }^{13}$ For a quick overview on Montague semantics, I refer the reader to Janssen (2006).

${ }^{14}$ I emphasise "inspired" here, since possible worlds proper (i.e. model-theoretic descriptions of states of affairs) play an important role only in logic. In mainstream (that is, qualitative) philosophy of language, 'possible worlds' are often nothing more than mere labels. Still, the reason to label certain strands of theorising as being, at least, 'inspired' by possible worlds talk is the following. Frameworks such as Borg's identify meaning with certain semantic cores, namely the respective equivalents to what has been labelled "character" by Kaplan. Characters are, essentially, functions from contexts (of utterance) to contents (referents). In other words, two main ingredients from possible worlds frameworks are still at work here. Firstly, contexts of utterance (or whatever you might call them) are possible worlds. So, by their very construction, these frameworks presuppose talk of possible worlds. Secondly, the main purpose of introducing characters (or their corresponding equivalents) is to have some stable semantic entity that ensures, for every context of utterance, that there is a specific referent that is picked out. This, I think, justifies conceiving of these frameworks as being heavily influenced by possible worlds semantics, even though they are not possible worlds approaches in the logician's sense.
} 
is exploited, so to speak, in meaning statements of the form "Term ' $x$ ' refers to entity $y$ ", in which the meaning of " $x$ " (and hence its use) is introduced by appealing to referential 'facts'. As I will demonstrate later, referential statements need not necessarily be true-i.e. recurring to facts-in order to successfully hint at a specific use. An example of a reference statement that is used to convey meaning is the following: "'The Morning Star' refers to Venus" (said to someone who knows what Venus is). It seems plausible to regard this as paraphrasing how "The Morning Star" is used. Depending on the background knowledge of the addressee of such a statement, she immediately understands an important aspect of how "The Morning Star" is used. Remarkably enough, this knowledge concerning use can be conveyed simply by making statements concerning referential facts ${ }^{15}$.

The "Venus" case exemplifies that appealing to referential relations may sometimes convey details about use only imperfectly. A competent speaker of English who learns that "The Morning Star" refers to Venus has learnt something about just one mode of presentation concerning Venus. "The Evening Star" is a term that is used differently, even though it shares its referent with "The Morning Star". Many philosophically important results can be drawn from this observation; in the present context, though, we are only interested in the role of reference statements (rather than in modes of presentation per se). Please note only that reference statements can be good approximations of how a given term is used. But they need not necessarily be the best such description. This, however, does not affect my main claim that meaning statements are paraphrases of implicit knowledge of use. This is because those aspects of ordinary reference statements that describe meaning 'correctly' are merely those aspects that recur to the use of a particular term. By the same token, reference statements like "Water' refers to $\mathrm{H}_{2} \mathrm{O}$ " are 'exhaustive', since they can convey-subject to the addressee's background knowledge-the entire use of a given term.

${ }^{15}$ Strictly speaking, not facts are important but what people take to be facts. If someone makes someone else familiar with the use of "water" in chemistry by saying that "water" refers to $\mathrm{H}_{2} \mathrm{O}$, then this 'meaning statement' in terms of reference might be successfulin the sense that the addressee has learnt how to use "water"-even if water 'turned out' to be something else (given a certain development in chemistry and given that, say, the causal-historical story about reference fixing (Kripke 1980) is true). I omit this complication in what follows and continue to talk simply about facts. 
However, this 'ability' is not restricted to reference statements. As in the translation case, such a statement may be taken as incomplete evidence for such-and-such a use of the word in question. For instance, the addressee might infer that "The Morning Star" will be used in contexts in which planets (not stars) are relevant, given the information that "The Morning Star" refers to Venus. Yet, note that this is only an assumption. The kind of inferences the potential addressee of a reference statement will draw depends crucially on what else she already knew about the language at hand. It seems quite instructive to compare this case with a situation in which some 'non-referential' information is learnt. Say, for example, that someone learns that "slacker" is considered rude. A possible inference to draw from this is to assume that "slacker" probably will not be used in the presence of women. But this is only a first guess-similar to reference statements. Which inferences an addressee will actually draw depends crucially on what else she knew beforehand.

The bottom line is that it might indeed be referential 'facts' that convey meaning sometimes, but only insofar as they are abbreviated ways of imparting (partial) knowledge about uses of words. It is a well-known fact about language that co-extensional words might have diverging Fregean senses, which is to say that the corresponding use associated with each word might differ (cf. "water" and " $\mathrm{H}_{2} \mathrm{O}$ "). This is why I emphasise "insofar" in this context.

Discourse: Discourses are notoriously hard to handle for semantic theories. One important difficulty is to model the reference relations that can be shared between different discourse units, such as the way anaphoric reference is transferred from sentence to sentence. Kamp \& Reyle (1993) present a model-theoretic possibility to represent discourse. Their approach-Discourse Representation Theory (DRT)-has set the standard in the field of discourse representation. Being part of the formal semantics movement, DRT covers only a limited set of discursive factors. In particular, it accounts for the linguistic context. DRT is thus able, for example, to represent anaphoric reference in successive sentences. A very simple representation in DRT (called 'Discourse Representation Structure'; 'DRS') might look like this: 


\begin{tabular}{|l|}
\hline$x$ \\
\hline Jones $(x)$ \\
{$[x$ own Ulysses] } \\
\hline
\end{tabular}

[... Like all DRSs it consists of two components:

(i) a set of discourse referents, called the universe of the DRS, which will always be displayed at the top of the diagram; and

(ii) a set of DRS-conditions, typically displayed below the universe. (Kamp \& Reyle 1993, 63, diagram also there)

Conceived this way, discourse representations are theoretically on a par with representations in truth-conditional semantics. Essentially, what they formalise is propositional content. It is for this reason that DRSs are not particularly illuminating concerning the natural sentences they are representations of. The representations are as illuminating as T-sentences: everyone who understands them, did so before. Their main purpose is to make explicit the formal relations that hold between sub-discursive units (e.g. sentences): anaphoric reference, implication, etc. That is, the explanatory aims of DRSs are, by their nature, severely limited. This generalises to all formal frameworks in semantics that confine themselves to mere truth conditions or representations of propositional content. Still, relative to the relations they formalise (e.g. anaphoric reference), discourse representations paraphrase meaning in that their adequacy is determined by how well they capture our pre-theoretic intuitions regarding these semantic relations.

Accordingly, the representations offered by DRT are clearly covered by my liberal, pre-theoretic definition of "meaning", since they reveal important aspects of language that are closely connected with use: which sentential inferences are valid; how words (e.g. personal pronouns) get and keep their referents through discourse; and so on. Still, it is equally obvious that a DRS like the one cited above is, in essence, nothing more than a very sophisticated way of saying that "Jones owns Ulysses" means that Jones owns Ulysses. It is quite clear that not all strictly formal approaches 
are alike in this regard. There are other, equally formal approaches to semantics that model specific semantic properties that cannot easily be read off from the natural sentences (or discourse) they are part of: see, for instance, the literature surrounding the range of possible interpretations for 'donkey sentences'16 (e.g. Geurts 2002) or semantic theories that account for semantically validated inference patterns (Pietroski 2000). The philosophically important point, though, is not whether a given theory deals with, if you like, 'transparent' aspects of meaning like anaphoric relations or with more intricate ones like competing interpretations of donkey sentences. Rather, the point here is whether the proposed definition of "meaning" in terms of implicit knowledge of use matches with (the notion of "meaning" used in) particular theories that apparently are established semantic theories-of which, by the way, the above-mentioned theories are only examples. Concerning formal semantic theories such as discourse representation theory and the like, the answer is a clear "Yes."

Lexicons: Lexical entries are prototypical examples of meaning statements. In fact, a lexicon just is a collection of meanings of words (if meaning is nothing over and above appropriate paraphrases). It is quite clear that lexicons are covered by my initial definition only if the lexicon is good enough, i.e. if it consists of descriptions that help otherwise competent language users to understand particular words, i.e. the entries of a specific lexicon.

In several respects, lexicons are unique in relation to semantics. For example, the trivial aspect that lexicons contain only meaning statementsthe lemmas-that are comprehensible relative to the very same linguistic system they are descriptions of. Another unique aspect of lexicons relates to what I will say below in the more theoretical chapters of this book. To anticipate a bit: below I will show that it will prove helpful to distinguish between what constitutes meaning and meaning itself (see the third part of this book). My proposal will be that word meaning is constituted by every single tokening of a word type. Meaning, in contrast, can be identified with the most general, most effective description of how that word type is used

16 'Donkey sentences' get their name from examples such as "Every farmer who owns a donkey beats it", which have two distinct readings (and hence truth conditions): every farmer who owns a donkey either beats all donkeys he owns, or he beats at least one of them. 
in a specific community (see especially section 8.2). It might turn out that many lemmas actually comply quite well with this requirement. If this is true, it would have some interesting consequences. For example, one important result could be that there might be no uniform code for appropriate meaning statements. For some words, it might be most effective to summarise their use in terms of reasonable examples, or by comparing it with meanings of related words, or in terms of its conversational function, and so forth.

Formalisms: I mention formalism here in order to demonstrate very briefly that formal semantic representations fit nicely with the proposed notion of meaning. I illustrate this by using a particular theory, which I already briefly mentioned above, as an arbitrarily chosen example: head-driven phrase structure grammar (Sag \& Wasow 1999). The considerations below, however, can be generalised to similar formalisms; they are independent of the niceties of this specific framework. Being a grammar theory, HPSG is not primarily concerned with semantics. Accordingly, questioning the status of semantics in HPSG seems like a cheap shot. However, semantics is not a mere by-product in HPSG. Therefore, it seems worth the effort to look at it in some more detail from the point of view of a theory of meaning. Semantic representations figure prominently in, for example, 'reference transfer'. Or, to put it differently, some syntactic features of English can only be accounted for by incorporating semantic operations, such as reference transfer, into one's grammar theory. HPSG is concerned with distinguishing grammatical from ungrammatical sentences. An exampletaken from Pollard \& Sag (1994) - of a problematic sentence that is classified 'grammatical' by native speakers is: "The hash browns at table six is getting angry". The problem is that the copula (singular) is incongruent in number with the subject ("hash browns"; plural). Very roughly, the solution is to say that in an 'ordering food at a restaurant' situation, reference is transferred from the actual denotation of the thing ordered (hash browns) to the person ordering it. Congruency with the copula gets then determined by the new referent (the person who ordered the hash browns). Hence, the singular form of the copula is the correct, grammatical choice in this example. What is important here is that semantics plays a crucial role, for syntactical features (singular vs plural copula) are influenced by semantic features (reference transfer). 


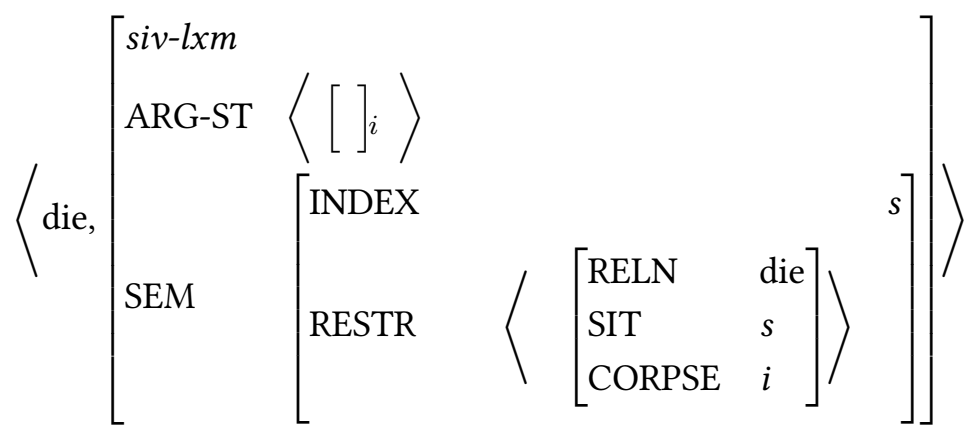

Figure 2.1: Lexical entry of "die" (Sag \& Wasow 1999, 394).

A lexical entry in HPSG (e.g. figure 2.1) is similar in important respects to 'normal' lexical entries like in the Oxford Dictionary or the (German) Duden. In contrast with these regular lexicons, the lexical entries of lexiconbased grammar theories focus on specific linguistic features only. This sets them apart from lexicons that contain comprehensive summaries of the use of given terms. However, there is no reason not to concede that theories like the HPSG model at least include important aspects of meaning-e.g. licensing a singular copula with plural subject in cases of reference transfer. In the example-"die"-it is quite obvious that an understanding of the meaning of "die" that goes beyond mere truth conditions is presupposed, because in the semantic part of the representation (SEM) we see that its meaning is the relation of dying (REL die). That is to say, you need to know what the relation of dying is in order to understand what the representation is a representation of. Compare this with a "die" lemma in an ordinary lexicon. The indices for CORPSE (apparently identifying the corpse) and SIT[UATION] only serve the purpose of tracking referents in the discourse (within and across sentences).

Generally speaking, when it comes to formalisms it is important which aspects are coded in the relevant representations. The most prominent information in the figure taken from Sag and Wasow is that "die" denotes the relation of dying. That is to say, it is made absolutely transparent that the 
formal framework of (this historical variant of) HPSG is not designed to reveal any specifically semantic aspects of its lexical entries. HPSG is, to be sure, first and foremost a syntactic theory, i.e. a theory that licenses particular phrases as grammatically well-formed ones. ${ }^{17}$ HPSG is at least not primarily concerned with semantics anyway. It comes as no surprise that the semantic features covered by the theory are therefore quite limited. ${ }^{18}$

Trivialism: A special case of theories that generate genuine meaning statements is what I dub 'trivialism'. A semantic theory is trivial if its meaning statements for particular words are derivable from the theory without any further knowledge about the object language. Horwich's 'use theory' can partly be seen as a theory of this kind. Consider the following quote:

The English word "dog" means DOG. (Horwich 1998, 14)

The quote shows that the capitalised spelling of words is understood in this framework as something like a placeholder, i.e. as something denoting the yet-to-be-specified meaning of a term. Horwich adopts a 'convention of capitalizing an English expression in order to designate its meaning or

${ }^{17}$ Note that, in HPSG, a sentence is a subtype of phrases:

A combination of a head with a further constituent is called projection of the head. A projection that involves all parts necessary to build a complete phrase is called a maximal projection. A sentence is the maximal projection of a finite verb. (Müller 2013c, 10, my translation)

So it is really just phrases that are licensed, even though it is equally possible to talk about sentences from within this framework.

HPGS is a lexicon-based approach, i.e. most of the syntactic information (and the complete semantics) is represented in lexical entries. This information is accompanied by a few general rules that specify how to combine lexical entries. Phrasal structures are licensed (that is, 'grammatical') iff their feature values are compatible. The theory builds complexes (genuine phrases and sentences) from the bottom up out of simpler units (lexical entries or simple phrases). Which units are grammatical is solely determined by the compatibility of the feature values of their constituents. The semantics does not interfere with grammaticality, i.e. its sole function in the theory is to keep track of referents (via indices) and to state which constituents provide which semantic aspects (e.g. referents for singular terms and pronouns; relations for verbs). The semantics is, if you like, 'transparent' and relies on constant meanings that are not affected by contexts: for example, "die" is semantically specified simply as [RELN die].

${ }^{18}$ For a modern derivative of HPSG, see, e.g., Fillmore (2013). 
meanings' $(1998,15)$. It is important to bear in mind that, although Horwich's book is full of statements like "Red' means RED”, the explanatorily relevant work is done by means of acceptance properties (see 3.1.1). In general, trivialism is always committed to explicating what is supposed to substitute the relevant placeholders. Some forms of trivialism, incorporating no placeholders, simply displace the burden of explanation from one area to another, e.g. by equating the semantics of natural languages with the semantics of their corresponding concepts.

Other trivial 'theories of meaning' are similar to Horwich's use theory in important respects. These theories specify word meanings in that they postpone the problem of word meaning to other areas of research. A very popular move is to talk implicitly as if concepts and the corresponding words that express these concepts can be identified in regard to their respective meanings. ${ }^{19}$ In this sense, then, these theories account for the meanings of words via a theory of mental representation. ${ }^{20}$ In these theoretical frameworks, the explanatorily interesting part concerns the linkage of mental representations and semantic content (especially reference). The identification of the semantics of a given word with the semantics of the specific mental representation that is expressed by this word is typically not focused by these theories. It rather has the status of a postulation. All mentioned theories, different as they are, share a trivial core: meaning statements are derivable either by applying a capitalisation convention (e.g. that "red" means RED) or by identifying the meaning of words with the meaning of mental representations (e.g. that "red" means RED). As far as this part of the theory is concerned, neither case requires any object-level knowledge whatsoever.

How can 'trivial' meaning statements be reconciled with our pre-theoretic understanding of 'meaning'? The 'trivial' part apparently can't be incorporated directly, for "RED" (as such) is nothing close to a paraphrase

${ }^{19}$ Fodor, for one, even goes as far as to claim that language inherits higher-order properties (systematicity, productivity) from concepts due to meaning identity (Fodor 1998, 26-27).

${ }^{20}$ Interestingly, the theories of meaning listed by Horwich as alternatives to his own theory are mainly such theories of mental representation: Mental Image Theory, Informational Theory, Teleological Theory (1998, 51-54). The main proponents Horwich thinks of here are probably Hume, Dretske, and Millikan, respectively. For a similar vantage point on semantic theories cf. Godfrey-Smith (1989, esp. section II). 
of how "red" is used. So whether trivial meaning statements are covered by my provisional definition of "meaning" depends on what the trivial statement is connected with. In Horwich's account, for instance, "RED" serves as a placeholder denoting the meaning of "red", whatever it is. The nontrivial part of the theory, then, gives us that the use of "red" is traceable to a specific set of acceptance properties. To wit:

The explanatorily fundamental acceptance property underlying our use of "red" is (roughly) the disposition to apply "red" to an observed surface when and only when it is clearly red. (Horwich 1998, 45)

Here, one can see clearly that certain sorts of trivialism fit quite nicely with the proposed definition of "meaning". Because this usage theory aims at providing every single word of a language, for example English, with a general property (expressed in terms of a disposition to accept certain sets of sentences) that paraphrases its use.

In the area of theories of mental representation, 'semantic' theories include all so-called informational (/teleological) theories (Dretske (1986) is a point of reference here), or theories of 'asymmetric dependence' (Fodor 1990). From the viewpoint of natural language semantics, these theories are trivial, because in regards to words they just equate their respective meanings with the meanings of corresponding concepts. For the present purposes, it is irrelevant whether this identification itself is plausible. I am only concerned with the fact that the semantics of words and mental tokens are very often thus identified in the philosophical literature. Here are some randomly chosen examples:

The speaker introducing the term says something like (or thinks, it doesn't matter), 'by "water" I mean [...]. (Levine 2010, 190, my emphasis)

To know English is to know, for example, that the form of words 'there are cats' is standardly used to express the thought that there are cats; and that the form of words 'it's raining' is standardly used to express the thought that it's raining [...]. (Fodor 1998, 9) 
[T] he expression 'that sofas are more comfortable than pews' provides the content of Alfred's belief that sofas are more comfortable than pews. (Burge 1979, 101)

If S thinks, or says, "The man in the picture was evil incarnate", whom is he referring to or thinking about: the unknown actor or Stalin himself? (Sosa 1995, 93)

Words have meanings, and thinking has content. [...O]ften I'll move carelessly among talk of meaning and content, the meanings of words and the identity of concepts. (Gibbard 2012, 26)

By postponing the problem of accounting for the semantic basis of words, this way of talking as if words and concepts were interchangeable parallels Horwich's placeholder approach. ${ }^{21}$

The question as to whether theories of this type paraphrase uses of words in the relevant sense and, hence, count as genuine semantic theories (in my sense) hinges on what takes the placeholder's place. Fodorian and Dretskian accounts of mental representation, for example, emphasise the causal nexus of concepts. More precisely,

Informational semantics generally ignores the actual history of a sign [of thought or language], and looks to what is a natural indicator of it. It is the mechanism of nomic dependence between sign and object that determines content. (GodfreySmith 1989, 535)

This way of approaching natural language is inspired by the 20th century dominance of truth-conditional semantics. For this reason, informational

${ }^{21}$ The parallel is even stricter than it might seem at first:

[...] the concept DOG is most directly identified as the concept that is normally expressed in English by using the word "dog" [...] (Horwich 1998, 98).

And, further down this page:

[...] the natural view that the meaning of an expression is the concept it expresses is quite consistent with the further claim that such concepts are identified by means of the use regularities of the words that express them. 
theorists stress, for example, the alleged referential facts of words. Thus, we have Fodor claiming that

The basic problem is that we want there to be conditions for the truth of a symbol over and above the conditions whose satisfaction determines what the symbol represents. $(1984,243)$

Being solely concerned with truth/falsity and related concepts (reference, fulfilment), informational theories are semantic theories that focus only on specific aspects of language. ${ }^{22}$ So, like formal semantics, the scope of at least some trivialist theories is severely limited in regard to semantic aspects.

Still, these theories are covered by my provisional definition of "meaning" insofar as, concerning natural-language semantics, they are tightly linked with non-trivial explanations such as Horwich's acceptance properties. Or, to put it another way: in the terminology of Speaks (2011), theories such as informational theory in fact belong to the area of foundational theories. On the other hand, subsuming the theories mentioned above under the heading 'trivialism' seems justified, because, in regard to the semantics of natural language (as opposed to mental representations), informational theory and similar frameworks are on a par with Horwich's capitalisation convention. The fact that "dog" is a symbol whose meaning nomologically depends on the existence of dogs is not immediately relevant to how "dog" is used. Therefore, informational-theoretic theorems do not illuminate the use of the expressions they are dealing with.

Ostensive Definition: Kripke's causal-historic theory of reference is another example of a theory that clearly belongs to the realm of foundational

22 'For Fodor, [semantics] is a relation between certain thoughts (beliefs, etc.) and the world, in virtue of which the thoughts are either true or false. Semantics, meaning, is about truth and falsity, period' (Dietrich 2001, 90). 
theories. The famous 'baptism ceremony' of "gold", though, is ambiguous between the 'foundational' and the 'semantic' reading. ${ }^{23,24}$ Kripke writes:

For species, as for proper names, the way the reference of a term is fixed should not be regarded as a synonym for the term. In the case of proper names, the reference can be fixed in various ways. In an initial baptism it is typically fixed by an ostension or a description. Otherwise, the reference is usually determined by a chain, passing the name from link to link. The same observations hold for such a general term as 'gold'. If we imagine a hypothetical (admittedly somewhat artificial) baptism of the substance, we must imagine it picked out as by some such 'definition' as, 'Gold is the substance instantiated by the items over there, or at any rate, by almost all of them'. $(1980,135)$

First of all, this is an explanation for why "gold" means what it does, i.e. it concerns its genesis. But it is also explains the meaning of "gold". The 'baptism ceremony' is, if you like, a special case of reference fixing, already discussed above. A speaker who performs such a ceremony commits himself to a certain use of "gold". That is, a proper description of the ceremony (plus Kripke's theory) is a paraphrase of how "gold" is used. Remember that I defined a 'paraphrase' as a description that provides competent language users with information about how the term is used. That certainly is the case for someone who is confronted with Kripke's story and issave for the meaning of "gold"-competent in English. Note that this is a precondition for the ceremony; because if the ceremony (or a description

${ }^{23}$ Kripke's story is not meant as describing what actually happened when "gold" was introduced for the first time, but rather as a description that simply is in accordance with the actual use of that term. His claim is that the semantics of, for example, "gold" looks as if that word had been introduced by such a ceremony. In this sense, Kripke's approach maps exactly onto what I said above about effective ways of summarising use. It might be that, in fact, the most effective method is by way of telling a fictive story.

${ }^{24}$ The distinction foundational/semantic is adopted from Speaks (2011), who says that ' $[. .$. a semantic theory [...] is a theory which assigns semantic contents to expressions of a language'. In contrast, a foundational or reductionist theory is simply a theory that specifies by virtue of which underlying non-semantic properties (e.g. use) the expressions of a language have the meanings they in fact have. 
thereof) did not imply a certain use, a speaker could not commit himself to a certain meaning of "water" by performing this baptism. Thus, ostensive definitions of the form "By ' $x$ ' I mean $y$ from now on" can be considered genuine paraphrases of how a term " $x$ " is or will be used. They are therefore absolutely within the scope of the proposed preliminary, pre-theoretic definition of "meaning".

It is evident from this cursory list of kinds of meaning statements that my definition of 'meaning as paraphrase' is broad enough to cover very different varieties of semantic theories and semantic aspects of related theories such as grammar theory. I am not, by virtue of provisionally employing this definition of "meaning", forced to adopt a particular (philosophical) theory of meaning. I shall show in later chapters that an order among theories in terms of appropriateness can be achieved by other means. Generally, the definition is as liberal as possible. It covers a broad range of different semantic representations that can all legitimately be considered to be dealing with relevant aspects of meaning. At the same time, the discussion of the proposed definition has already hinted at some problematic areas. These include purely formal approaches, e.g. truth-conditional semantics, discourse representation theory, teleological semantics, and so forth. Theories of this kind work with a constrained notion of meaning; or, in other words, they deal only with quite specific aspects of meaning (most prominently, reference). Their theorems consist of semantic representations that hardly go beyond what can already be read off from the relevant linguistic signs they are representations of.

It goes without saying that the list of theories chosen for the above overview is incomplete. Yet it is broad enough that one extrapolate from this list that the proposed pre-theoretic definition of "meaning" is compatible with all meaning statements that figure in mainstream theories in linguistic semantics and philosophy of language.

\subsubsection{Primary Meaning and Compositionality}

In semantic theories in general and in philosophical semantics in particular, compositionality is a key concept. Here, I focus particularly on the relationship between compositionality and the classical conception of primary meaning in terms of reference, as both notions seem to partially justify 
each other (see the following paragraph). The 'correct' formulation of the compositionality principle is still controversial (e.g. Gendler Szabó 2012a, Gendler Szabó 2012b). Most scholars, though, would typically subscribe to the view that compositionality is a feature of language, according to which the meaning of a complex expression is systematically determined by the meaning of its atomic parts and their mode of combination. This characterisation should suffice for present purposes; I continue discussing compositionality in 5.2.3.

Compositionality usually presupposes fixed lexical meanings of atomic parts of one's language (e.g. words). For otherwise there could be no 'mechanism' (i.e. the syntax) that, starting from meanings of words (i.e. semantics), could help determining the meaning of complete sentences. A quick argument for primary meanings could therefore run as follows: that natural languages are compositional is a widely accepted view; the compositionality principle is by far the most commonly accepted solution to compositionality; the principle is, inter alia, based on the assumption that there are fixed lexical meanings (e.g. meanings defined in terms of reference/satisfaction). Therefore, compositionality lends indirect support to the assumption of ordinary literal meanings. Independently of how this quick argument is spelled out exactly, it seems clear that there is a very close link from compositionality to literal meaning. One of the aims of this book is to argue against the common assumption that words always 'have' a literal meaning irrespective of the contexts in which they are instantiated. Accordingly, it looks like a good idea to explicate the exact nature of the relationship between literality and compositionality, for there must be something in my own theoretic framework that can serve as a substitute for literal meaning. Accordingly, I shall propose in the following a definition of "primary meaning" that, on the hand, is capable of handling literality/nonliterality issues, and, on the other hand, does without assumptions that usually go hand in hand with primary meanings (e.g. the assumption that words literally refer).

When it comes to compositionality and the justification for why we think that natural languages are compositional, Fodor (e.g. Fodor \& Lepore 2002 ) is our first port of call. I shall briefly remind you of his main argument. Clearly, natural languages seem to be productive and systematic 
to a large extent. ${ }^{25}$ Productivity, in the sense at stake here, is the phenomenon that an infinite number of well-formed complex expressions in natural languages can potentially be understood by speakers who are competent in the relevant language. In other words, there are an infinite number of grammatical sentences, all of which are potentially comprehensible for those who understand the involved semantic atoms and composition rules. Systematicity is the common property of languages that every competent language user who understands a given sentence and recognises its structure is similarly able to understand other grammatical sentences that result from rearranging the relevant constituents. For example, competent users of English who understand "John loves Mary" are likewise able to understand "Mary loves John". Both systematicity and productivity requirefor reasons not be further examined here-a language that features atomic semantic units (e.g. Fodor \& Lepore 2002).

To sum up thus far: two main reasons motivate the concept of primary meaning. Firstly, the distinction held up in linguistics as well as in philosophy of language between semantics and pragmatics. ${ }^{26}$ Secondly, the compositionality of natural languages and the corresponding principle that accounts for it. It is a view on meaning widely shared by linguists and philosophers of language alike. What is important in the following examples is not that the respective arguments are based on the compositionality assumption but, rather, that the respective authors presuppose stable lexical word meanings:

[...] it is part and parcel of the compositionality of English that the symbol 'John jumps' is complex, that it has among its constituents the symbols 'John' and 'jumps', and that its meaning (viz., John jumps) is inherited from the meanings of these subsentential parts. (Fodor \& Lepore 2002, 1)

\footnotetext{
${ }^{25}$ Problematic cases, which seem to show that natural languages are, at least, not systematic all the way down, will come into play later on. For example, it seems that the semantic content that "white" contributes to "white wine" differs from the content it contributes to complexes such as "white Socrates" or "white wall". Suffice it to say for now that systematicity seems to be prevalent in at least large areas of natural languages.

${ }^{26}$ Gendler Szabó (2006), Heusinger \& Turner (2006), Jaszczolt (2012).
} 
[...] "dogs bark" somehow gets its meaning [...] from the meanings of the two words "dog" and "bark", from the meaning of the generalization schema " $n \mathrm{~s} v$ "27, and from the fact that the sentence results from placing those words in that schema in a certain order. (Horwich 1998, 154)

[Our hypothesis] is that the process by which a speaker interprets each of the infinitely many sentences is a compositional process in which the meaning of any syntactically compound constituent of a sentence is obtained as a function of the meanings of the parts of the constituent. (Katz 1966, 152)

The denotation of an adjective is always a function from properties to properties. [...] The standard denotations of many adjectives-for instance, $\ulcorner$ green $\urcorner$ and $\ulcorner$ married $\urcorner$-may be taken as intersection functions [...]. (Montague 1974, 211, emphasis omitted)

What is striking about the typical examples that theorists choose when characterising compositionality is that they are very simple. A typical sentence might be "University buildings are ugly", which, presumably, consists of four constituents, namely "university building", "-s", "be" and "ugly". The noun denotes university buildings, the suffix denotes plurality, the copula itself is, in the interpretation involved here, more or less semantically empty (basically, it functions as a syntactic device that 'enables' predication), ${ }^{28}$ and "ugly" denotes unattractiveness. The syntax of English, in

27 " $n$ " is for 'noun'; " $v$ " is for verb.

${ }^{28}$ Below I will be discussing many interesting examples of allegedly meaningless expressions. Depending on one's theory of meaning, copulas might also turn out to be meaningless after all, for they contribute nothing substantial to the semantic content of a complex expression. Rather, the 'meaning' of the copula seems to consist solely in its functionality: that is to say, it indicates that two other expressions stand in a certain relation to each other. Roughly, the copula function is to indicate that the thing denoted by the grammatical subject is among the things that has the property denoted by the predicative noun (or anything along these lines). To be sure, that is its meaning. But, arguably, the only way to state its meaning in these terms is in theories that recognise that the meanings of at least some terms consist solely in their function, which many philosophically interesting theories do not, after all. 
conjunction with the meanings of the sentence constituents, gives us, or so it is claimed, the meaning of the complete sentence.

In the above example, this procedure might tell us that the property of unattractiveness is predicated of the plurality of university buildings and, hence, that the sentence is true iff university buildings are ugly. This pretty straightforward-and for ease of presentation, slightly simplified-strategy is, essentially, what truth-conditional semantics says is actually going on. I will show in the chapter after next that this way of approaching semantics is a bit too straightforward. Of course, it is always justified to choose a simple example in order to get one's point through without annoying the reader with unnecessary technicalities and complexity. But in the cases typically chosen in characterisations of compositionality, the simplicity is unjustified. The reason is that such a strategy only works if what is explained at the level of very simple sentences is applicable analogously to more complex sentences. This seems questionable in these cases, for reasons having to do not with the complexity or length of sentences but with the semantics of the words occurring in them.

In particular, the unjustified move is to generalise from a very limited class of words of speech to whole natural languages. Typically, the parts of speech chosen include proper names and verbs functioning as predicates. The semantics for these is then provided more or less in the style of the example above ("university building" means 'university building', and so on). All this is intuitively compelling but ignores the problem that not all of semantics can be cashed out this simply. Think of truth-valueless sentences, for instance. They clearly have meaning-if well-formed. Look, for example, at the following, still very simple example: "Hey, Mrs Robinson!" Presumably, this sentence, although well-formed, is not truth-evaluable, i.e. no truth conditions can reasonably be assigned to it. The common move here is to switch from truth conditions to 'satisfaction-conditions', because it is not the former but rather the latter that can account for some classes of non-declarative sentences such as interrogative or imperative sentences. ${ }^{29}$ But this would not help either in cases of exclamations like the one cited. The meaning of such an exclamation is best described in terms of the conversational function associated with exclamations of this type: along the

${ }^{29}$ Although that is the probably most popular strategy, there are also alternatives. 
lines of 'is used to express one's interest in a good social relationship'. However, it looks highly counter-intuitive to describe this function in terms of satisfaction/fulfilment, e.g. by saying that "Hey, Mrs Robinson!" is satisfied iff such-and-such conditions hold. This is because a command is, with conceptual necessity, satisfied iff the conditions specified in the command actually hold. But the analogy with exclamations breaks down 'at all levels', so to speak: the meaning of "Hey, Mrs Robinson!" remains the same, no matter whether the addressee's social relationship with the speaker alters; or whether the addressee recognised that this was the speaker's intention; or whether it indeed was her intention; and so on. So, whereas the move to satisfaction-conditions is at least consistent in the case of imperative sentences, it is implausible in the case of exclamations that regulate social status. The fact that "Hey, Mrs Robinson!" is not truth-evaluable is unproblematic as far as it goes. But the deeper problem is that, on the one hand, "Hey, Mrs Robinson!" seems intuitively compositional, whereas, on the other hand, all existing philosophical theories of meaning-from Davidson semantics to Horwich's use theory-focus on truth-evaluable sentences ${ }^{30}$ and how these sentences derive their meaning from corresponding constituents. An established philosophical account of the meaning of purely 'functional' expressions-e.g. exclamations that clarify social status-is still missing. This is a problem that generalises to the huge class of types of sentences that, in general, lack truth-evaluable content. ${ }^{31}$

${ }^{30}$ For sake of simplicity, I continue to talk of sentences here. Bear in mind, though, that at least some of the problematic cases can be, strictly speaking, individuated in terms of their corresponding force, i.e. in terms of speech acts rather than sentence types. For example, interrogatives are types of sentences (they can be described formally), but wishes are types of speech acts (they can only be described with regard to accompanying intentions); what 'unites' them is that they both lack truth conditions but (probably) possess satisfaction conditions.

${ }^{31}$ That is to say, there is a huge class of sentences that are incapable of being 'themselves' truth-evaluable. It is possible to link expressions which lack truth value with some other expressions that do not, where the latter are supposed to express the 'right' truth conditions for the former. The theories that adopt this idea provide truth conditions for some expressions by taking into account their use conditions. Here is an example: "Hello!" might not be truth-evaluable. But of course there is a certain use condition associated with "hello". For example, is used to maintain social relationship'. David Kaplan, for one, proposes something along these lines (see https: //www . you tube . com/wat ch?v=iaGRLlgP16w, accessed: 14/01/2015). 
To take another example, think of gestures, which must be included into an exhaustive account of natural language semantics. ${ }^{32}$ Surely, many of them have meaning-e.g. iconic gestures. Moreover, they surely equally have meaning in the sense of 'constituents' of complex expressions. Here is an example of a complex communicated content whose meaning is 'composed' of individual meanings that are partly established by gesture (roughly, 'being annoyed' and 'I'm referring to this person'):

In an airplane, I take my seat on the aisle. There is a woman sitting next to the window in my row. A man comes into the row behind us, talking extremely loudly and obnoxiously. I look to the woman and roll my eyes, expressing an attitude best glossed as "Ugh, this is going to be a long trip." I did not need to indicate the referent of my exasperation for her; it was clear to us both. (Tomasello 2008, 80)

It is hard to see what lexical meanings of gestures (here: rolling of the eyes) would look like, if they were such that they could then be used as a basis for an explanation of the complex meaning. A comprehensive account of compositionality must cover cases like these, since not all natural language sentences consist of simple subject-predicate structures. ${ }^{33}$

Truth-valueless sentences as well as gestures are two problematic areas in the field of compositionality. They indicate that the simplicity of examples typically chosen to describe how compositionality works is not just a matter of style but, rather, an unjustified simplification as regards parts of speech (or, generally, types of 'communication signs'). This, in turn, undermines the plausibility of justifying ordinary primary meanings by recurring to compositionality principles. For there must be a way to accommodate (some kind of) 'compositionality' in the cases discussed abovei.e. a strategy that does without the classical compositionality principle, which is inappropriate for gestures and sentences with specific functions (as opposed to truth-evaluable content). Prima facie, there is no need to

\footnotetext{
${ }^{32}$ I argue for this in 2.2.3 and 2.2.4.

${ }^{33}$ I devote a large portion of the third part of this book to a discussion of the standard reply that, for sake of simplicity, I ignore at this point: namely the worry that while pretending to talk about semantics, I actually talk about communication all the time.
} 
assume that this modified manner of conceiving compositionality must involve primary meanings spelled out in terms of reference relations. Hence, the indirect support for primary meaning that might arise from the classical compositionality principle seems unjustified.

It is clearly not the aim of this chapter to decide this matter, nor even to suggest a possible direction between the two extremes: full-flavour primary meaning versus no primary meaning at all. Rather, the purpose of the above paragraphs was to present evidence pointing, as it were, in both directions. Save for the critique of compositionality in the very last paragraphs, all the above was 'in favour' of primary meaning. Thus, in the next section I now turn to the cons.

\subsection{Constructionist Approaches to Semantics}

One of the most influential paradigms in linguistics today is construction grammar. It aims at 'developing a comprehensive model of linguistic structures that is [...] a universal theory of representation, acquisition, and change of linguistic knowledge' (Ziem \& Lasch 2013, 1). One of its linguistically most relevant aspects is that it starts linguistic theorising by looking at language phenomena that are conceived as peripheral from a more classical point of view (e.g. idioms). However, from a philosopher's perspective, another feature is by far more interesting: namely, construction grammar's tendency-discussed below-to neglect a clear-cut boundary between semantics and pragmatics as well the denial of such a strict boundary in the case of semantics and syntax. In construction grammar, pragmatic and syntactic information is generally represented in essentially the same framework in which semantics is represented. This development fits quite nicely with a more general tendency in philosophy of language (cf. François Recanati's work on 'truth-conditional pragmatics' (2007)) and in the research of language acquisition (cf. Michael Tomasello's work on 'joint attention' (e.g. 2009)) $)^{34}$ to shift the divide between semantics and pragmatics more and more towards pragmatics. In other words, in these research paradigms, semantics typically includes elements that would fall into pragmatics in more classical frameworks (cf. Recanati's treatment of

${ }^{34}$ See also Butterfill (2012) and Pacherie (2011). 
'what is said'). After a very brief overview of the theoretical background, I turn to some more specific issues, in particular to multimodal compositionality, i.e. the linguistic phenomenon that many modalities contribute to utterance meaning at once.

\subsubsection{Construction Grammar: From Cognitive Semantics to Philosophy}

In linguistics, construction grammar $(\mathrm{CxG})$ has attracted more and more attention over recent years. I shall only briefly summarise the main theses of the theory. For detailed expositions, I refer the reader to Fillmore (1993) and Goldberg (1995). ${ }^{35}$ CxG deviates significantly from the standard. The most important thing is that no strict distinction is drawn anymore between the lexicon and the syntax. ${ }^{36}$ Lexical and syntactical information is still encoded (and differentiated), but both 'kinds' of information are handled in largely the same manner, i.e. both are represented in the form of constructions. Constructions are form-meaning pairings, the simplest of which are morphemes. Accordingly, all linguistic information is stored, not in the lexicon and the grammar, but in what is often called the 'constructicon' (Goldberg 1995, 5). In similar fashion, construction grammar dismisses the semantics/pragmatics distinction. This is particularly important for the present discussion, because of the close relationship between this very distinction on the one hand and primary and derived/pragmatic meaning on the other hand.

One of CxG's major principles is that every sign is a form-meaning pair. Interestingly, syntactic constructions are treated as bearing their own meanings-contrary to all alternative approaches in which syntactic rules map meanings of lower-level constituents (morphemes, words, phrases) onto complex meanings. Such rules usually do not bear their own meanings, the meaning of a complex expression-eventually, the meaning of a

${ }^{35}$ The list of obligatory standard references includes: Croft (2001), Fillmore (1988, 1988), Goldberg (1995, 2006), Langacker (1987), Lakoff (1987, 467-858). Comprehensive overviews can be found in: Fischer \& Stefanowitsch (2007), Lasch \& Ziem (2011), Lasch \& Ziem (2014), Stefanowitsch \& Fischer (2008), and Ziem \& Lasch (2013).

${ }^{36}$ Besides the mentioned standard references, the presentation developed here and in the following is heavily inspired by the comprehensive overview in Ziem \& Lasch (2013). 
sentence-depends solely on the meanings of its parts (Tomasello 2003a). In $\mathrm{CxG}$, all form-meaning pairs are constructions: from words to particular syntactic arrangements. A construction is recursively defined as follows: ${ }^{37}$

$\mathrm{C}$ is a construction iff $\mathrm{C}$ is a form-meaning pair $\left\langle\mathrm{F}_{i}, \mathrm{~S}_{i}\right\rangle$ such that some aspect of $\mathrm{F}_{i}$ or some aspect of $S_{i}$ is not strictly predictable from C's component parts or from other previously established constructions. (Goldberg 1995, 4)

Before I turn to the discussion, let me just very briefly give you an impression of what a constructionist representation of linguistic information looks like. The formal apparatus of (some theory families of) $\mathrm{CxG}$ stems from head-driven phrase structure grammar. Although there are, as far as linguistic analysis is concerned, subtle differences between HPSG and $\mathrm{CxG}$, they are similar and often even equivalent in regards to their representation format (Müller 2013b, 248-253). ${ }^{38}$ The details do not matter here, this is just to give you the flavour of what we are talking about. The most important thing is that both grammars represent linguistic information as attribute-value matrices. The attributes encompass both syntactic and semantic information. The respective representations license certain structures in such a way that a complex expression (a phrase, a sentence) is grammatical iff the corresponding attribute-value matrices of its parts are compatible. They are compatible, basically, if their values match, or, otherwise, if one of two corresponding values is left unspecified. A simple example would be a case in which you already have a representation of a verb phrase that lacks only a subject to form a complete sentence. The verb

37 This is the 'standard definition'. A newer version, also from Goldberg, is broadened in that entrenchment is explicitly allowed as a sufficient criterion for constructions, even in cases in which their meaning is otherwise predictable from other constructions (Goldberg 2006, 5). Linguistically, this difference is significant; from a philosophical point of view, it is not particularly relevant in the present context. Here I am primarily interested in whether the research paradigm of construction grammar is compatible with established theories of meaning in philosophy. As far as that compatibility is concerned, there does not seem to be a difference between Goldberg's two definitions of "construction".

${ }^{38}$ Other CxG variants that are less inspired by HPSG are sometimes characterised as 'cognitive' (Ziem \& Lasch 2013). If not indicated otherwise, the differences between individual construction grammars are irrelevant for my argumentation. 


$$
\begin{gathered}
\text { Transitive Construction } \\
\text { SYN }\left[\begin{array}{ll}
\text { CAT } & v \\
\text { VOICE } & \text { active }
\end{array}\right] \\
\text { VAL } \left.\left\{\left[\text { ROLE }\left[\begin{array}{ll}
\text { GF } & o b j \\
\text { DA } & -
\end{array}\right]\right]\right\}\right]
\end{gathered}
$$

Figure 2.2: Representation of Transitive Construction (Müller 2013b, 242).

phrase, then, constrains the possible values of the subject. For instance, it might demand a noun phrase that meets certain requirements. The result of applying a compatible noun phrase to the verb phrase is a sentence licensed by the grammar (assuming that the verb phrase was constructed accordingly). To put it more generally, the grammatical sentences in $\mathrm{CxG}$ are exactly those constructions that are built up from compatible lowerlevel constructions, with morphemes probably being at the lowest level.

As I already noted, in construction grammar everything from words to syntactic structures is represented as constructions. The 'Transitive Construction', for instance, might look like figure 2.2.

Here you can see the representation of linguistic information by means of attribute-value matrices. The function, so to speak, of the construction is to restrict the possible values of certain attributes. In this case, it restricts the value of 'DA' (distinguished argument) to '-', which just means that it is that argument that would not be the subject of the sentence in active voice. All these linguistic details do not matter for the moment. What is important to note is that the grammaticality of complex constructions is determined according to the values of lower-level constructions. Plus, syntactic restrictions are encoded on a par with semantic information.

When it comes to semantic theories in philosophy, the discussions often develop independently from actual linguistic theories. This holds in particular for grammar theory. The thing is, though, that developments in linguistics need to be taken into account by philosophers of language working in semantics-a truism, actually. Otherwise, one's theory is likely 
to lack empirical underpinning. This is a general point that not only concerns semantics but also, for example, language acquisition. You might think that philosophers are dealing only with non-empirical questions and, therefore, issues negotiated in philosophy of language are largely independent of findings in the sciences, in particular in linguistics. This is fine as far as it goes. It is fine if the claim is only that there need be no 'direct' connection between both theories in such a way that the results of one theory are deployed in the respective other theory. ${ }^{39}$ This is so because there is no data that we would need to account for by combining philosophical and linguistic views on semantics.

However, if the claim is that both areas are completely independent, then it is probably false. Generally, philosophical theories in semantics must be compatible with results produced in empirical disciplines such as linguistics, psychology, anthropology, etc., i.e. these theories and their philosophical counterparts should not contradict each other (cf. also 7.1.3). Some general considerations justify this claim. The most general background assumption is that one's (philosophical) theory calls for psychological (/linguistic) reality. Let us first have a look at language acquisition theories. In philosophical terms, acquisition theories belong to the realm of foundational (or reductive) theories, i.e. they are theories that explicate the underlying properties that constitute semantic properties (Speaks 2011). In this case, they explicate the underlying properties that amount to the ontogeny of semantic competency. For example, a foundational theory would explain the origin of the relationship that holds between, for example, (the word type) "apple" and its corresponding meaning, i.e. 'apple'. A given theory of meaning must be compatible with one existing acquisition theory-this will typically be the currently accepted theory-for the following reason.

Assume it were incompatible with all acquisition theories. The latter describe how we, human beings, come to speak a language with certain features. If both theories were incompatible, two cases may be distinguished. First case: either of the theories might be false. If the semantic theory were false, that would be bad news anyway. So we may ignore this case. To assume-all else equal-that the psychological theory could be false be-

${ }^{39}$ Like when the laws of optics and of physics are combined to interpret observations of the Sun via telescopes. 
cause of its assumed incompatibility with a competing philosophical theory is highly implausible. For "false" in this context may be taken to mean, roughly, 'empirically falsified'. Ex hypothesi, the psychological theory is the only empirically informed theory (of the two). To take incompatibility with a non-empirical theory as evidence for empirical inadequacy is unjustified. One is therefore justified in excluding this option. The second case is: the philosophical theory might not call for psychological reality. This option would allow for contradiction between the theories in question, since however language actually is acquired according to the psychological theory, the philosophical theory might be just one way of accounting for the available data. This looks like a possible strategy, but is has an evident drawback. Since language acquisition theories are the only theories that explain how natural languages are acquired, every theory that is incompatible with these theories and that denies any call for psychological reality could not possibly be a theory of our language (e.g. English). It might be a theory of something similar (i.e. grammar-wise superficially similar, but acquired differently); however, finding a theory of meaning that fits with actual language use is an 'all-or-nothing game', as it were. Explaining something 'similar' to natural language is not explaining natural language at all.

Mutatis mutandis, the same reasoning applies to the relation between philosophical and linguistic theories of meaning. They also need to be compatible. The only case in which they could end up being incompatible is when the philosophical theory is a product of 'armchair philosophy', i.e. the result of (and only of) a priori methods. For if both are empirically informed and both deal with the same subject matter, then there can't be any 'competing' theories, strictly speaking. As a matter of fact, it should always be possible in such cases to favour one theory over the other on the basis of objective criteria of theory choice (simplicity, universality, elegance, etc.). Naïvely speaking, there can always be only one best theory in the empirical realm (in the long run), in which case there is no actual 'competition'. In real life, this is a bit more complicated, because, for example, people tend to disagree about the appropriate set of theory choice criteria, or they disagree about how to apply them to a particular case. Be that as it may, if any of the two approaches is empirically adequate, it is the linguistic theory. As above, no matter what the philosophical theory is 
dealing with in such a case, it is not English (or, for that matter, any other natural language). Therefore, if one wants to account for the semantics of natural language, one better ensure that the philosophy fits in with current linguistics.

Another background assumption is that empirical evidence is a means of theory choice. All else equal, if two competing philosophical theories are to be evaluated, one of which contradicts current linguistic theories, then the respective other theory is better off. Conformity of philosophical theories with empirical theories can always be regarded as indirect evidence for empirical adequacy, for the scientific success of the latter heavily depends on their adequacy. A final important background assumption concerns contradictions between theories. Firstly, theories within semantics differ significantly as towards the notion of 'meaning' they involve. Secondly, there are huge differences in regard to the semantic descriptions in philosophical theories and scientific theories. One assumption needed in order to establish the claim that theories of both kinds must be compatible is that there is a way of how to verify whether this is the case or not. Without further argument, I assume that this can be done. I shall show in what follows that this is unproblematic.

This digression serves the purpose of preparing an argument for the rather strong connection between empirical and philosophical theories. The important thing to note is that if you claim your theory to be about the semantics of natural languages in the form they are actually used, you better make sure it is compatible with the relevant empirical theories. This is where $\mathrm{CxG}$ comes into play. This is, for obvious reasons, not the right place for a detailed discussion of the status of $\mathrm{CxG}$ within linguistics. ${ }^{40} \mathrm{Of}$ course, the argument to follow ultimately depends on the success of construction grammar, since there is no apparent incongruence between the assumption of primary meanings and other grammar theories (in particular, Chomskian generative grammar). So, the argument against primary meaning at hand hinges on the empirical plausibility of $\mathrm{CxG}$. Be that as it may, there will always be competing theories and $\mathrm{CxG}$ is just one of many.

\footnotetext{
${ }^{40}$ Müller (2013b,237-258) reviews the current state of construction grammar and provides a comprehensive bibliography on the subject matter. Stefanowitsch \& Fischer (2008) is an introductory textbook focusing solely on CxG. The most recent overview in English is Michaelis (2006). Again, the most recent overview is Ziem \& Lasch (2013).
} 
In a nutshell, the weakest claim to be defended in the following is this: all else equal, a philosophical theory of meaning is better off if it dispenses with the ordinary notion of primary meaning explicated in terms of reference. $^{41}$

Given the recent popularity of construction grammar in linguistics, it is worth the effort to see whether the theory is compatible with established philosophical (semantic) theories. For the moment, though, I will focus on a particular aspect of the theory, namely its connection to ordinary primary meaning. The success of $\mathrm{CxG}$ might be interpreted as evidence against referential semantics, this is because there is no place within the theory for any such notions as reference relations and truth-conditional functions (se also above). The most obvious counter-evidence is that one of the arguments for primary meaning can be reversed: I have shown that the semantics/pragmatics distinction justifies primary meanings, because, very roughly put, pragmatic meaning 'derives' from stable lexical meaning (i.e. primary meaning). In construction grammar, on the other hand, the semantics/pragmatics distinction vanishes. 'Officially', it is still there, i.e. the values of constructions are labelled accordingly. But no principled distinction is made any longer; the pragmatic 'principles' are handled as if they were semantic information:

It seems appropriate to allow the notion of compositionality to comprise [...] 'pragmatic' instructions embedded in the grammar that provide the addressee with a certain semantic structure and instruct him or her to find content in the context that satisfies that structure. Consider utterance of a sentence like [the following]:

Kim won't (even) get question eight right let alone Sandy get question nine.

[...] In this example, we have to think that the problems can be arranged on a scale (presumably of difficulty) and students arranged on a scale (presumably of ability) where the scales are interrelated in such a way that a more able student will

${ }^{41}$ Here I am tacitly assuming that this leaves compatibility with other grammar theories unaffected. 
answer correctly any problem that a less able one will and a less able student will miss any problem that a more able one misses. (Kay \& Michaelis 2012, 2283-2284)

It is no trivial matter where exactly to draw the distinction between semantics and pragmatics. ${ }^{42}$ In any case, though, semantics is the study of meanings. Or, more precisely, semantics is the study of lexical, contextindependent meaning ${ }^{43}$, if you single out the meanings of particular utterances in particular circumstances as an independent field of study (which would then be pragmatics). Interestingly, you need not be exactly clear about where to draw the line between semantics and pragmatics in order to establish the claim that in construction grammar, the distinction is more or less obsolete. ${ }^{44}$ This is because $\mathrm{CxG}$ still employs meanings in its 'lexical' representations of constructions. That is to say, by their very definition, constructions are form-meaning pairings and, therefore, they all have meaning. No matter what you take pragmatics to be, it certainly encompasses a distinct class of pragmatic 'principles' ${ }^{45}$. These principles or pragmatic regularities, however, are incorporated into constructionists' meaning representations (see Kay \& Michaelis (2012) and Ziem \& Lasch (2013, 14, 25-26), for example).

To be fair, many constructionist analyses ignore pragmatic issues to a large extent. These are either left out completely (e.g. Michaelis 2006), or they are mentioned only in passing (e.g. Kay \& Michaelis 2012). ${ }^{46}$ Still, if pragmatics is part of one's analysis, then the findings are modelled as

${ }^{42}$ See Gendler Szabó (2006) for a review.

${ }^{43}$ Note that the context independence of meanings is independent from the context $d e-$ pendence of the expressions modelled. For instance, a formal-semantic description of the meaning of "this" might essentially be 'context-dependent' in that it describes how the referent of "this" depends on context. The meaning itself, though, is independent from any such context (e.g. 'refers to what's most salient in the relevant context').

44 'More or less' because, judging from the terminology used by construction grammarians, one may easily get the impression that the distinction still plays a role.

${ }^{45}$ In particular, principles that involve references to intentional explanations-e.g. 'If the speaker utters something obviously false, he must mean something different'. Classically, Gricean maximes count as paradigm examples of pragmatic principles.

${ }^{46}$ Cf. also Östman $(2005,125)$ :

Very little has been done on pragmatics proper and discourse proper in relation to Construction Grammar. It is often recognized that there is 'some- 
part of the construction in just the same way as semantic information is represented: ${ }^{47}$

The $\mathrm{CxG}$ notation relies on three major devices: ${ }^{48}$ boxes-withinboxes diagrams for representing constituent structure, feature structures for detailed grammatical information, and co-indexation for keeping track of unification relations. [...] syn $[\ldots]$

prag constructional pragmatics \& information-structure specifications

val semantics of the construction

phon [...] (Fried \& Östman 2004, 25-26)

In similar fashion, some constructionist approaches combine $\mathrm{CxG}$ representations with data drawn from conversational analysis. This is relevant to our present discussion for the very same reason as in the case of pragmatics proper: normally, one would want to explain the meaning of a given term in a particular conversational situation by referring to primary meanings. However, this strategy is again unavailable here because conversational aspects of meaning are already included in the constructions from which sentence meaning is derived in the first place. As before, this makes it seem rather implausible to assume that one's basic semantic units can have primary meaning in the sense of mere reference relations. ${ }^{49}$ Here

thing' more out there, but what it is has largely remained a waste-paper basket.

${ }^{47}$ Cf. also Wide $(2009,131)$. Fried \& Östman (2004) discuss the format of construction specifications more generally (see especially pp. 25-76).

${ }^{48}$ In this general form, this claim is probably untenable. For one thing, this might be correct for HPSG derivatives of $\mathrm{CxG}$ (cf. their mentioning 'unification relations' here), but it is certainly false for most 'informal' sketches of construction grammar, especially those in the tradition of spoken-language research.

49 The reader who is worried that I might confuse issues of communication with issues of semantics is asked to have a look at chapter 8 before reading further. 
is an example of how conversational aspects are modelled within a $\mathrm{CxG}$ framework:

form:

communication partner: turn (TRP) speaker: PM but-clause

meaning:

topic continuity

successful contact, perception, understanding acceptance of contribution

solidary interpersonal function (Fischer 2013, 200)

\section{The 'Turn-initial Pragmatic Marker' Construction ${ }^{50}$}

It is irrelevant for the argument at hand that not all varieties of construction grammar incorporate pragmatic or conversational aspects. Even those approaches that focus solely on semantics, largely ignoring the actual communication situation, acknowledge the role played by context. It is just that this aspect is often left out of the analysis. In principle, contextual factors may be modelled in all variants of the $\mathrm{CxG}$ family. Moreover, in the case of formal varieties such as sign-based CxG (Michaelis 2013) or fluid $\mathrm{CxG}$ (Steels 2011), pragmatics is often excluded for reasons of convenience, although its relevance is widely accepted in principle.

This means that, if one wants to stick to the semantics/pragmatics distinction, pragmatics becomes-at best-part of semantics, i.e. roughly in the sense that semantics would be the study of meanings, while pragmatics would deal with a certain subclass of them. Apparently, such a weak notion of pragmatics is, in fact, not solid enough to back the idea of cashing out primary meaning in terms of reference relations. In the argument

50 "TRP" is short for "transition relevance place", "PM" stands for "pragmatic marker" (like "yeah" or "okay"). The terminology of the items listed under 'meaning' stems from conversational analysis and is more or less self-explanatory. "Solidary interpersonal function" refers to what is usually known as 'face-saving strategy', i.e. communication acts that serve the purpose of signalling politeness against the interlocutor, the one from whom the turn had been taken. 
for primary meaning that is based on the semantics/pragmatics distinction, pragmatics plays the following role: starting with mere preference relations, the pragmatic principles are functions from contexts to meanings in context. Such a procedure presupposes stable lexical meanings. In $\mathrm{CxG}$, however, although there is still pragmatics, there are no such relevant 'principles', i.e. nothing that takes meaning (plus $x$ ) as input and yields (other) meaning as output. Accordingly, the way pragmatic information is handled in construction grammar is inappropriate to support the ordinary notion of primary meaning recurring to relations of reference.

This is not to say that a theory framework such as construction grammar, which does not allow for a principled distinction between semantics proper and pragmatics, still allows semantic information to play the same role as in other frameworks. Semantics can only be the input of pragmatic rules if indeed there were such rules. For example, if the intonation of "a is F" were such that it triggered an ironic interpretation, then that interpretation would be that 'a is non-F'. Conversely, if there were no such rules, there is no need for semantic information to serve as 'input' to such processes. Hence, no matter what the distinction between semantic and pragmatic information in constructionist theories (other than being labelled 'semantic' and 'pragmatic', respectively), it is not the traditional one-that information of the former kind serves as input to processes of the latter kind.

\subsubsection{The Tomasellian Programme}

Another argument against primary meaning stems from developmental psychology. Tomasello and colleagues have stressed repeatedly the importance of gestures for the ability of (human) animals to develop a language (e.g. Tomasello 2008). Developing gestures as simple communication signs is an initial but very important step towards this end, they claim. At first sight, this seems quite irrelevant for the question at hand. But it is not, as I will show in a moment. One important background assumption in what follows is that when it comes to semantics, gestures and other communication signs-typically, words and sentences-are handled on a par, i.e. no principled distinction is or can be drawn between them with respect to their 'ability' to contribute to complete utterances. From this, one may infer that if there are primary meanings, gestures have them (assuming 
primary meaning is a universal feature of natural language signs). Thus, if we are able to show that gestures do not exhibit primary meaning, this allows us to infer that gestures provide counter-evidence against primary meaning. Therefore, the task is to show that this is actually the case: gestures can hardly have primary meaning, if primary meanings are supposed to represent relations from signs to the world.

For a start, consider the following randomly chosen examples:

A man in a bar wants another drink; he waits until the bartender looks at him and then points to his empty shotglass. Gloss: Attend to the emptiness of the glass; please fill it up with liquor. (Tomasello 2008, 63)

At a loud construction site, one worker pantomimes to another ten meters away as if he were using a chainsaw. Gloss: Imagine me doing this; bring me the thing I need to do it. (68)

The examples are supposed to show two things: firstly, the 'meaning' of a given gestural sign varies enormously from one occasion to the other; secondly, no formally specifiable context dependency can account for this. The first observation, I take it, is more or less clear. So, let me concentrate on the second.

In all of the following, I take for granted that this is not the right place to defend the merits of Tomasello's research agenda. For the most part, I will restrict myself to merely reporting on his view-and to draw those conclusions that are relevant to philosophical theorising, given the results established by Tomasello and his colleagues. Given this, let us return to the question why there are many gestures for which it seems impossible to trace back their meaning to some formally specifiable context dependency. Why not assume gestures work like indexicals? you might ask. We have theories of how to handle indexicals, so there is no problem with gestures. ${ }^{51}$ If the context sensitivity of gestures could be captured by characters,${ }^{52}$ nothing could prevent us from saying their meanings were primary.

${ }^{51}$ There is a massive amount of literature solely dealing with indexicals. The locus classicus in this context is Kaplan (1989).

52 "Character" is Kaplan's now-classical term for a function from contexts of utterance to truth-conditional content. The basic idea here is that the meaning (as opposed to its se- 
Granted, their primary meanings are not lexical meanings, strictly speaking, but the same holds for the meanings of usual indexicals like "this". Just provide a context of utterance and you immediately get full-blown meaning including reference, which then may be used, relative to a given set of pragmatic rules, to derive meanings in context. This strategy suffers from the following shortcoming: in a nutshell, it is impossible to state appropriate characters of gestures.

Let me explain. The character of a term or gesture-i.e. meaning minus contextual values-must be describable in such a way as to cover all possible cases. That is to say, its semantic description needs to be weakened so as to be applicable to all counterfactual circumstances (contexts) in which the term may be applied. This sounds a bit abstract; a simple example will help to clarify the idea. A term with a 'normal' (complete) meaning is "Chris", for instance. It simply denotes the person called 'Chris'. A term like "he" might be described as already 'weakened' in the following sense: although we do not know, independently from context, its complete meaning (at least not its (actual) reference), what we do know is quite a lot. Namely that, in all contexts, "he" would usually denote the last male person mentioned in the discourse (be it a conversation, a text, or whatever). This meaning is fixed (I assume) and fairly complete. Even 'weaker', then, is the semantic description we have of a term like "this". As with "he", we do not know (in advance) its reference. But this time we actually know even less, as linguistic rules alone do not suffice in this case to determine the actual referent. The contextual information must include also non-linguistic data: information about pointing gestures, for instance.

Primary meaning is the information about an atomic semantic unit of our language that we have prior to encountering specific instances. The semantic information is, as I have just demonstrated, relatively limited in

mantic value in specific contexts of utterance) can be defined or characterised in terms of token-reflexive rules. For instance, "I" gets associated with a rule such as "The semantic value of an instance of 'I' in a given context is the speaker of 'I' in that context". The 'token-reflexivity' lies in the fact that the meaning of a given token of an indexical expression can't be stated without referring to the same token again. Defining the character of "I" is comparatively easy; "here" and "now" (and cognates) are significantly harder to define, as their actual referents (relative to contexts of utterance) arguably depend on a variety of background assumptions shared between speaker and hearer (e.g. world knowledge). The locus classicus for indexicals more generally is Perry (1986). 
the case of "this" compared to "Chris". Nevertheless, it is there. It might be characterised thus: "this" designates the object that is contextually most salient, with salience being determined by the linguistic context and a corresponding pointing gesture.

The point is that, when it comes to gestures as such, it is questionable whether it really makes sense any more to speak of meanings proper (though it is not completely incomprehensible to do so). I have shown that in order to determine the complete meaning of (a token of) "this", one needs to know its character (e.g. "the most salient object in the vicinity') plus further linguistic information (the discourse into which the token is embedded) plus contextual information (information about bodily movements of the speaker $)^{53}$. The 'character' of a gesture is, in the sense described above, even weaker, i.e. almost no information about the meaning of a gesture tokening is available beforehand. The relevant information thus always needs to be read off the specific situation in which a gesture gets instantiated. This is apparent if one takes a look at Tomasello's examples. In addition to all the information necessary in the case of indexicals, one needs to know the 'common ground' shared between the relevant interlocutors. Common ground is knowledge about the situation that is shared by the participants of a given situation (Tomasello 2008, ch. 3). ${ }^{54}$ The cited examples strongly suggest that the stable, lexical part of meaning (i.e. meaning minus context minus linguistic information minus common ground) would be so thin that it seems absurd to take this for the 'primary meaning' of a given gesture.

If you assume that the primary meaning of a pointing gesture is that which is contextually salient depending on the linguistic embedding, the context including bodily movements of the speaker, and the common ground of the participating speakers, then this amounts to saying that you know hardly anything in advance. It could be just anything. Contrary to "this", one does not even know for sure that the referent is a (concrete) object of

\footnotetext{
${ }^{53}$ If you find pointing gestures or bodily movements unconvincing, you may amend the list of contextual information that is necessary to compute the whole meaning of a term, in particular its referent. This just complicates the issue but does not affect the point at hand.

${ }^{54}$ Horton (2005), Liebal (2009).
} 
any sort. The gesture might even denote a situation. For example, consider the following scenario:

Suppose that I and you are walking to the library, and out of the blue I point for you in the direction of some bicycles leaning against the library wall. Your reaction will very likely be "Huh?," as you have no idea which aspect of the situation I am indicating or why I am doing so, since, by itself, pointing means nothing. But if some days earlier you broke up with your boyfriend in a particularly nasty way, and we both know this mutually, and one of the bicycles is his, which we also both know mutually, then the exact same pointing gesture in the exact same physical situation might mean something very complex like "Your boyfriend's already at the library (so perhaps we should skip it)." On the other hand, if one of the bicycles is the one that we both know mutually was stolen from you recently, then the exact same pointing gesture will mean something completely different. Or perhaps we have been wondering together if the library is open at this late hour, and I am indicating the presence of many bicycles outside as a sign that it is. (Tomasello 2008, 3)

So one interpretation offered by Tomasello is that the pointing means 'Look! Your boyfriend is still in the library!' (given appropriate background assumptions). Notably, there are an infinite number of possible interpretations and, hence, objects, in the broadest sense, that might be denoted by particular gestures, because there is an infinite stock of background knowledge that might be shared by the participants in a discourse. As I already said, this is no conclusive argument against the ordinary way of conceiving of primary meaning. It is just supposed to show that if you are ready to call this 'primary meaning', you must be defending a very weak notion of lexical meaning that allows for some atomic signs to possibly denote almost anything.

Besides, the assumed 'meaning' of a pointing gesture is incomplete anyway, I suppose. Because even if it worked, the only thing it would do is determining the reference. While being one of the major components of meanings, it is at least questionable whether reference really is everything 
interesting about semantics. Note also that some important details have been skipped over by subsuming different things under the heading 'pointing gesture'. The second example ('construction site') involves so-called 'iconic gestures', which contribute (propositional) content that goes beyond mere reference. The question, then, is how to individuate different gestures. How many are there? When are two gestures type-distinct? Are the meanings of all types of gestures learnt separately? These are nontrivial questions, which one needs to answer if gestures are supposed to have primary meaning.

To sum up, gestures represent a second example of empirical evidence against primary meaning conceived of as reference relations, given that gestures are treated on a par with words. According to Davidson's distinction between a prior theory and a passing theory (Davidson 1986), what enters into the former are primary meanings, the things we know about the meaning of a sign prior to a situation in which it is used. I have shown that in the case of gestures this amounts to saying that primary meanings could be so thin as to allow for just any denotation. Therefore, the quintessence of the evidence collected above in regard to Davidson's 'prior/passing theory' distinction is that one's 'prior theory', i.e. the kind of information available before one enters into a specific communication situation, can't possibly consist solely of knowledge of reference relations and truth-conditional functions.

\subsubsection{Multimodality}

Keeping the above discussion of gestures in mind, it seems natural to link these results with the discussion of compositionality. The semantic framework that will emerge throughout this book is based on the assumption that utterance meaning, as opposed to mere 'sentence meaning', plays a crucial role in semantics. In this view, describing the mechanism by virtue of which actual referents of referring expression are determined is part and parcel of a theory of meaning. In this regard, gestures figure prominently, as they 'contribute' essentially to utterance meaning. More importantly, gestures contribute to utterance meaning in virtue of having specifiable meaning. In light of these considerations, there seems to be an interesting link from compositionality back to gestures, which will be discussed be- 
low by contrasting it with classical views about reference fixing. Gestures thus far have played a very marginal role in linguistic semantics and especially in philosophy of language. ${ }^{55}$ The only theme occurring from time to time in work on indexicals is indeed reference fixing. ${ }^{56}$ A typical instance of which would be:

That $<$ pointing gesture $>$ is a table.

Actually, starting from pointing gestures used to fix reference gives me a good opportunity to motivate the relevance of gestures for semantics in general. In the above example, a pointing gesture-which deliberately is not specified any further-serves the purpose of singling out an entity in the immediate visual vicinity. The semantics of indexicals is commonly given in terms of a token-reflexive description along the lines of

"This" used in context $c$ refers to the entity that, when "this" is uttered, is the most salient entity in $c$.

The means employed to 'achieve' salience are diverse. In the easiest cases, the linguistic context (i.e. usually the immediately preceding sentences) uniquely qualifies a specific entity as the most salient one relative to this particular context. In cases where the linguistic context does not suffice to disambiguate "this", reference is typically fixed by accompanying gestures, normally a pointing gesture. A third possibility, of course, is that a given entity is the most salient one in a context even without being made so either by verbal nor non-verbal signs. A simple example of this variant would be a thunderstorm suddenly approaching in an otherwise average situation: for example, two people standing on a meadow on a sunny afternoon when one of them, shortly after a loud noise, gives a quizzical look. If, in such a situation, the other person were to say "That's a thunderstorm",

${ }^{55}$ Though see Gärdenfors \& Warglien (2013).
${ }^{56}$ For example, Newen (1996) points out that

If one of a variety of equally salient objects is highlighted by a pointing gesture of the speaker, then the deictic expression occurring in a corresponding demonstrative utterance refers to that object that is highlighted by this pointing gesture. (1996, 87, my translation) 
the reference of "that" would not need to be fixed by any extra means, be it verbal or non-verbal. The context makes the thunder salient all by itself. All this, to be sure, requires a lot of additional theory 'in the background' in order to work properly. Most importantly, one would need to have an account of 'standard contexts', which is hard to get anyway. Also, the mechanisms by which entities 'increase' their salience relative to contexts are not sufficiently clear up to now. Most remarks in the literature are suggestive at best in this regard. For instance, if the context is altered accordingly, it is not that clear any more that a pointing gesture to a table, executed by the current speaker, makes the table the most salient entity. Altering the context means altering the standards according to which something counts as more or less salient. Besides the issues involved with standard contexts and salience, it is, in general, unclear whether the object referred to is the most salient one in the first place. For example, Borg (2004b) discusses the relevance of speaker intentions in determining referents. Her conclusions differ from my own, since, for example, reference fixing for her is not a proper aspect of semantics. ${ }^{57}$ Be that as it may, reference fixing seems to involve a lot of different aspects: standard assumptions, salience, speaker intentions. ${ }^{58}$ However, all these background assumptions are not particularly relevant for the present issue. For the moment, allow me to just take for granted that some account or other can be developed that can handle these problems.

A pointing gesture can be conceived as bearing its own semantics. Seeing pointing gestures (and other gestures) that way helps in understanding how they figure in human communication and is indeed a necessary con-

${ }^{57}$ Her basic idea here is that establishing actual referents is a matter of utterances and, hence, important only for communication. Actual reference, in her view, can only be resolved 'post-semantically' via intention-reading processes. The realm of semantics is restricted to just those aspects of meaning that are 'available' independently from contexts of utterance, i.e., roughly, Kaplanian characters. In the present context, what is relevant is that Borg acknowledges that, still, actual referents are determined by contexts, broadly construed (including intentions and intention ascriptions).

${ }^{58}$ Whereby I do not want to invoke the impression that speaker intentions can directly alter meaning (as in Humpty Dumpty scenarios). Rather, the claim is that the use of indexicals can only be explained by assuming that speakers are guided by certain intentions (and assumptions about which intentions are recognisable by typical interlocutors, and so on), and that hearers' interpretations are intention-guided as well. I return to this in 8.3. 
dition for understanding gestures at all. To see what we are getting at, let me first recapitulate how pointing gestures figure in classical semantic theories in philosophy. The meaning of "this", as I illustrated above, can be determined independently from what exactly determines salience in a context. Its meaning can be stated in terms of a rule that relativises its reference to a particular context. The pointing gesture, on the other hand, contributes to the semantics of the overall utterance only by chance: any other means that similarly would have increased salience in that context would have had the very same effect.

Compare this with the semantics of "() is a table", which arguably in most philosophical accounts of meaning is an open sentence which requires only one more constituent, which determines the reference, to make a full sentence. Truth-theoretically speaking, "() is a table" is true iff the entity to which the expression that fills the argument position refers is a table. The pointing gesture does not contribute to the semantic value in any reasonable sense. The only thing it 'does' is make some entity or other salient (or more salient at any rate). The semantic contribution needed to turn "() is a table" into a complete sentence-and hence, in a particular context, into a complete utterance-is the one by "this".

This view underestimates the semantic contribution of gestures to the semantics of whole utterances. The thing is that many gestures are significantly more complex than mere pointing gestures (Mittelberg \& Waugh 2009, Müller 2013a). Many gestures even have properties that are typically considered defining features of verbal signs (e.g. conventionality). Gestures interact in very different ways with verbal signs and contribute in interesting ways to the semantics of utterances. Still, let me start with pointing gestures first. Pointing gestures are never used without communication intentions. Classifying arm movements as 'pointing gestures' implies that these arm movements serve certain purposes. ${ }^{59}$ It might even be true that their main purpose is increasing the salience of particular objects in given contexts (the ones pointed to, probably). Be that as it may, pointing ges-

${ }^{59}$ For the moment I will be focusing specifically on arm movements. These are the most important pointing gestures. It is possible to point to some entity by using other parts of the body, e.g. by moving one's eyes or legs. For sake of simplicity, I restrict myself to arm movements though. Everything I shall say is intended to equally apply to other bodily movements. 
tures, qua being pointing gestures, do not occur outside of communication contexts. In other words, classifying something as a pointing gesture implies that what matters is communication.

\subsubsection{Compositionality Applied to Multimodality}

My above comments are based on the assumption that different types of semantic units (words, gestures, intonations, postures, facial expressions, and so on) share a common sense in which they are meaningful. Put another way, since meanings are ultimately nothing over and above descriptions, meaning statements concerning different meaningful types are theoretically on a par.

Ultimately, the objects of study of a theory of meaning are utterances. ${ }^{60}$ Several types of 'signals' contribute to the overall meaning of utterances. This aspect of semantics is called multimodality. A problem arises as soon as one tries to link multimodality with compositionality. In classical theories of meaning, the meaning of a word like "pet" (i.e. 'pet'), when it gets compositionally combined with the meaning of "fish" (i.e. 'fish'), must be 'pet fish' (that is, the meaning of "pet fish"). Considerations like these normally serve the purpose of defeating particular theories of meaning: since, for example, a prototypical pet is a dog and a prototypical fish is plaice, the prototype theory is claimed to be false (Fodor \& Lepore 1996), for a prototypical pet fish is a goldfish. ${ }^{61}$ For the present purposes, these considerations are irrelevant though. The point is just the following: "pet" and "fish" belong to the same domain (linguistic signs). So it is relatively straightforward to see how they can be combined to form larger units. When it comes to multimodal compositionality, however, the question is: how can semantic descriptions of different modal domains be integrated into one compositionally combined semantic description of a full utterance?

${ }^{60}$ This is highly controversial. I give a detailed justification in 8.2.3 and 8.3.

${ }^{61}$ There are a lot of tacit assumptions at work here, all of which, however, are irrelevant in the present context. For example, one central assumption in the argument is that compositionality ensures that, e.g., prototypes combine compositionally: the meaning of a compound expression is, or so the argument goes, the 'sum' of meanings of its constituents. I ignore these niceties here, as 'ordinary' examples of compositionality are mentioned here only to serve as a starting point for my discussion of gestures. 
The only reasonable solution seems to be reverse engineering, because the only available information to start with is utterance meaning, i.e. the 'end product' of communication processes.

Reverse engineering is a method of ascertaining the production process of an object by deconstructing the end product. For example, (there are people who think that) Chinese engineers copy German cars (e.g. Mercedes's GL) by first trying to find out how the end product was built. They have no access to the relevant construction plans; they are thus forced to work with the car itself as their only source of evidence. In the present case, the end product is utterance meaning; the construction plans are the atomic semantic constituents and their mode of composition. Reverse engineering applied to linguistics means: deconstructing utterance meaning-which is given-into its constituents. In the case at hand, the task is 'simplified' by the fact that parts of the 'construction plans' are already known. We know the meaning of the verbal constituents of multimodally composed utterances. This amounts to saying that in these cases, the meaning contributed by a gesture must be utterance meaning minus verbal aspects.

Here is a toy example that illustrates this. Instantiations of "that" in conjunction with a particular pointing gesture have (relative to specific background assumptions) a determinate referent. Typically-though not necessarily-the object referred to is the object pointed at. Notably, establishing reference is achieved by combining the interpretations of pointing gestures and of the word "that". Reference is an integral part of semantic theories; therefore, assigning interpretations to gesture and verbal sign in such a way that their combination can uniquely determine a particular reference is primarily a semantic task (and does not belong to pragmatics). Given that the reference is known, determining the semantic contribution of verbal and gestural sign means finding two appropriate interpretations that, if combined, yield the desired output (the object referred to, which, by assumption, is given).

The solution along the lines of classical theories in philosophy is quite boring, though illuminating. It will serve as my starting point. Semantic theories that are particularly designed to handle indexicals often use indexes (see above). In indexicalist accounts, indexicals are expressions with 
certain indices (of which the obvious ones are time, place, speaker). ${ }^{62}$ The index values determine the context of utterance. The indexical "that" is a function from contexts of utterances to extensions. In natural language, the character of "that" can be characterised thus:

"That", uttered by speaker $S$, usually refers to the entity that is most salient in the relevant conversational context. ${ }^{63}$

In this reading, "that" is a term whose semantics is somehow unsaturated. In particular, one is in a position to figure out its referent only relative to the relevant contextual cues. ${ }^{64}$ The semantics of "that" in conjunction with the semantics of the pointing gesture determine the semantic value of a particular "that" utterance. Accordingly, the semantics of a pointing gesture thus must be something like the following:

${ }^{62}$ In fact, time, place, speaker, and anaphoric reference are typically the only contextual features that get incorporated into a formal theory of meaning. Borg (2004b, e.g. pp. 5262) stresses that intentions, in particular, are difficult to handle in formal approaches. I think, though, that her reservations apply, in effect, to all potentially 'interesting' contextual cues such as common ground, world knowledge, plausibility assumptions, default assumptions, co-text, knowledge concerning one's interlocutors, social conventions, and so on (i.e. interesting in that they are relevant for fixing actual reference).

${ }^{63}$ For ease of presentation, I omit other potentially relevant contextual factors such as time and place. Also, I simply take for granted here that "salience" can be defined rigorously. This, of course, is a topic on its own.

${ }^{64}$ Cf., for instance, Higginbotham (1994, 92-93):

[...] the truth conditions of sentences with context-dependent elements are themselves conditional, dependent upon the satisfaction of conditions that are not in general represented in utterances of those sentences. Consider an utterance with demonstrative 'this' in subject position, a form that places no categorial limits upon the referent, and is limited in context only by the requirement that the referent be appropriately proximate. If the utterance is, say, 'This is red' then (ignoring tense) the conditional truth conditions are [as follows]:

If the speaker of 'this is red' refers with the utterance of 'this' therein to $x$ and to nothing else, then that utterance is true if and only if $x$ is red. 
A pointing gesture, in the majority of cases, serves the purpose of increasing the salience of the object towards which it is directed.

This leads to the intermediate result that an instance of "that" plus pointing gesture towards object $x$ supposedly refers, ceteris paribus, to $x .{ }^{65}$ Note two things: firstly, my description of how "that" gets its reference can be considered to be more or less uncontroversial, for everything said thus far is just making explicit what is implicit in, e.g., Kaplanian semantics, anyway. Secondly, it is not particularly difficult to 'combine' two descriptions, although they concern two totally different domains (linguistic sign vs gesture). I will illustrate below how easily this generalises to other cases.

Crucially, the effect of executing a pointing gesture can sometimes be achieved by linguistic means. One could just equally increase the salience of an entity by, for example, describing it. Still, it is important to bear in mind that modal-specific signs are not equivalent in meaning to the linguistic expressions that are their corresponding descriptions. An immediately evident example is irony. Metaphorically speaking, irony 'reverses'

${ }^{65}$ The CP clause is required here because the 'meaning' of a pointing gesture is, by its nature, underspecified. That is, the salience of which object exactly is increased by a given instance of a pointing gesture necessarily depends on further, potentially unknown, factors. To take a variant of Borg's $(2004 b, 178)$ example: if I point at a CD cover, whereby I increase, very roughly, the salience of this cover, the addressee still does not know to which object my corresponding "that" tokening refers. Exactly this is at stake here: the meaning of pointing gesture in conjunction with an indexical. I could be referring to the $\mathrm{CD}$ cover, the artist, the picture, the music style, and so forth. All of which depends on my-the speaker's-intentions, and the recognition thereof. In this particular example, there are arguably two further 'classes' of information that might be relevant. One is the question as to which kind of thing is salient in this particular context anyway-independently from the pointing gesture as such. For instance, which topics did I mention in the previous conversation? Another one is the basis for my decision to consider this specific pointing gesture an appropriate means of directing the addressee's attention to a particular object (cover, music style, etc.). For example, am I familiar with the addressee's background knowledge ('world knowledge'), and am I justified in thinking that, on the basis of this knowledge, the addressee is likely to be able to figure out the actual referent? So there are a variety of factors that influence the actual referent of an indexical in conjunction with gestures, which are at least partly underdetermined by the two clearly identifiable constituents. In other words, the process of reference fixing of indexicals is context-dependent in a way that goes beyond those features of contexts of utterance that are formally specifiable such as time, place, and speaker. 
the propositional content that is expressed 'literally'. There are certain typical triggers for irony, one of which is intonation. A linguist might describe the meaning of an intonational pattern that typically triggers ironic readings by saying that this particular pattern means 'What I'm saying is meant ironically'. Everyone would understand such a description. And everyone would understand, based on this description, the use of the intonational pattern at hand. However, saying that 'what I'm saying is meant ironically' has quite a different effect on one's audience than using this pattern.

Hence, although gestures and the like sometimes substitute linguistic signs, they are definitely not equivalent to them all the time. The linguistic description is always just an approximation. The better my interlocutor is able to understand a gesture (or the like), based on how I describe its meaning, the better the description. Which is to say that the problem of compositionality in the domain of multimodality can't be solved by simply 'substituting' the gesture with a semantic description that corresponds to or approximates it. Gestures, in other words, have their own semantics.

Salience as the link in reference fixing between the semantics of indexicals and the corresponding 'contribution' of gestures is just one option among many. For instance, Borg (2004b, passim) repeatedly emphasises that finding out about actual reference is a matter of communication (not semantics), in particular a matter of reading and ascribing intentions. In regard to indexicals, she defends the view that '[c]ontext-dependent expressions have a lexical entry which merely specifies a rule for generating a token expression's truth-conditional contribution' $(2004 b, 166)$. This works quite well for her own example, "I": if $x$ utters "I", then this token refers to $x$. It is also relatively straightforward for the case of "that" relativised to salience: if $x$ is the apparently most salient object in the vicinity of a speaker uttering "that", then this token refers to $x$. By itself, the assumption that determining reference is primarily a matter of intention-reading ${ }^{66}$ seems very plausible to me. The problem lurking here is that one needs to specify the 'conditionalised T-sentence' for "that" (analogously to "I"). In particular, if intentions are the pragmatically relevant factor in determining the actual referent in a specific context, then the conditionalised semantic rule associated with "that" must inevitably recur to intentions as well. Roughly,

${ }^{66}$ See, e.g., Borg $(2004 b, 209)$. 
along the following lines: if $x$ is the object an utterer of "that" wanted to refer to, then this token refers to $x$. In this case, the 'contribution' of a pointing gesture might not be increasing salience (as such), but rather to indicate the particular object to which the speaker wanted to refer. ${ }^{67}$ At this point, I only want to span the logical space of possibilities. So I shall leave the detailed discussions to later chapters. Let me just note here that this example already shows that incorporating gestures into one's semantics is far from trivial.

For compositionality to start off, a common format of meaning representation is required. This common format might be descriptions of use in natural language. I showed how straightforward it is to 'compose' utterance meaning, given the context-related, underspecified meanings of "that" and pointing gestures. On the other hand, it is hard to imagine alternative, more sophisticated possibilities that would not recur to use. I have concentrated on the simplest possible case, and even in this case, use plays the essential role in that it determines which factors increase salience and thereby fix the relevant reference. It is even clear that this salience-increasing factor is implicitly taken for granted in classical theories of meaning, which lends further support to it.

Now for more complicated cases. Examples include:

- Emphasis (gesture, pause, intonation) (e.g. Bartels 1999)

- Referential/iconic gestures (e.g. Indefrey \& Gullberg 2010)

- Code-switching sign language/natural language (e.g. Emmorey, Borinstein \& Thompson 2005)

- Multimodality in general (e.g. Cienki \& Müller 2008, Müller, Cienki, Fricke, Ladewig, McNeill \& Teßendorf 2013)

- Gestures expressing propositions (e.g. Streeck 2009)

In prefaces, introductions, and the like, people very often declare that their respective theories only deal with 'meaning' in a specific, limited sense. The above list of examples of cases of multimodal compositionality is likely

${ }^{67}$ To be sure, increasing salience is one way of doing this. 
to invoke the impression that 'meaning' is understood here in a sense that deviates from this standard. The worry could be that the present proposal might be too permissive. Accordingly, my aim in the following is to show that the way I employ the term "meaning" crucially accords with the established practice.

To be sure, showing this amounts to nothing less than saying a few words about what a semantic theory is in the first place. First and foremost, a semantic theory is a theory that is about the meaning of communicative acts (cf. section 7.2.1). Accordingly, without even defining "meaning" more precisely, one may already exclude cases like "This means the end of the Cold War", which clearly involve the metaphorical sense of "meaning". The really interesting cases concern, for example, facial expression. I want to defend the view that facial expressions have meaning in exactly the same sense as words have meaning. This is, to say the least, not obvious. However, the refusal to accept anything as meaningful units other than words, sentences, phrases, and morphemes, for example, is rooted in biases, I think. The three most important ones are probably: focus on declaratives; focus on written language; focus on literal meaning. Focussing on these three elements gives a distorted picture of which underlying properties one expects to find in the area of semantics.

From a pre-theoretic stance, the central notions of modern theories of meaning-intension/extension, truth-evaluability, inferential validity, etc.look somewhat counter-intuitive. At least pre-theoretically, one would think that a theory of meaning should cover the whole range of available evidence in the realm of meaningful entities. That is to say, a theory (i) should be guided by all available evidence and (ii) should account for all observable phenomena in the semantic domain. An unbiased view on language includes, among other things, recognising that a large amount of human communication takes place orally; that a great portion of human communication is non-verbal; that truth-evaluability is relevant for a minority of cases even in written language; and that language use is, to a large extent, often imperfect, rhetorical, ad hoc, etc. This is pretty close to a moral that Tarski drew in his classic 1944 paper, in which we read that:

The problem of the definition of truth obtains a precise meaning and can be solved in a rigorous way only for those languages 
whose structure has been exactly specified. For other languagesthus, for all natural, "spoken" languages-the meaning of the problem is more or less vague, and its solution can have only an approximate character. Roughly speaking, the approximation consists in replacing a natural language (or a portion of it in which we are interested) by one whose structure is exactly specified, and which diverges from the given language "as little as possible." (Tarski 1944, 347)

The crucial point in this polemic is that he acknowledges that he considers his theory to be fundamentally inapplicable to natural languages (in their present form). For a start, English seemingly contains 'its own' truth predicate, i.e. a predicate that is applicable to sentences of the very same language it itself belongs to. In this sense, Davidson's project of turning a Tarskian theory of truth into a Davidsonian theory of meaning seems to contradict one of Tarski's most basic assumptions. The problem is not just that the 'natural' truth predicate differs from the one envisaged by Tarski. The more fundamental problem is that even the most basic theoretical ingredients-the meaning stipulations for singular terms and predicatesare disentangled from natural language semantics.

A quite illustrative example is vagueness. The 'base clause' for "chair", for example, is: $x$ satisfies "() is a chair" if and only if $x$ is a chair. But whether that is actually the case in English depends on which objects people actually apply "chair" to, i.e. it depends on use. Probably, the verbal behaviour of many people diverges with respect to "chair" and chairs. That is to say, whether the cited base clause is accurate depends on whether the meaning we as theoreticians attach to its right-hand side matches the meaning of "chair" in the idiolect of that person to whom knowledge of the base clause is ascribed. Davidson assumes that features like productivity can only be accounted for if we assume that people have implicit knowledge of Tarskian theorems. ${ }^{68}$ Davidson's solution to this, namely to posit

${ }^{68}$ In Davidson's own terms:

[...] a theory of meaning for a language $L$ shows "how the meanings of sentences depend upon the meanings of words" if it contains a (recursive) definition of truth-in-L. And, so far at least, we have no other idea how to turn the trick. $(1967,310)$ 
that both sides of the T-biconditionals are semantically equivalent by definition (Davidson 1967, 314-318)-i.e. to say that we are dealing with interpreted sentences-amounts to saying that we are not dealing with (actual) natural language after all. This is because only formal languages are interpreted languages in the relevant sense. ${ }^{69}$ People just have passed on certain expectations that shape their definition of "meaning". My justification for taking a more liberal stance towards this definition is: we need to clarify the appropriate order first. That is: let us examine the phenomena first, then start theorising, not the other way around. The phenomena-some of which I just listed-simply require that we recognise that certain elements have meaning. ${ }^{70}$

Consider the following example: someone says "Nice weather!" By making an accompanying facial expression, she indicates irony. Accordingly, her respective interlocutor would understand that she, the speaker, is under the impression that the weather is bad (here and today). The facial expression must mean 'Attention, irony!' because if the whole utterance means 'Bad weather!' (as it does by assumption) and "nice" and "weather" can't be solely responsible for this (which, again, they can't by assumption, since "nice" plus "weather" means, all else equal, 'nice weather'), then something else must be in charge of eliciting this interpretation. Nothing is simpler than assuming that the meaning at hand is composed of the meanings of "nice", "weather", and the facial expression.

Thus, in the conception of "meaning" defended here, people, when they understand other peoples' signals, do nothing more than implicitly associate a certain use with these signals. Building on this understanding, it is not hard to see how people 'compose' meaning across several modalities. They just use facial expressions to indicate, e.g., irony, just as they would use any other means with which they could achieve the same aim, including utterances of the form "I mean this ironically". Concerning multimodality, the original problem is thus not solved but postponed. Since description of use already is a common format of meaning representation, it is not more prob-

\footnotetext{
${ }^{69}$ I am assuming "interpreted sentences" defined along the lines of, e.g., Stalnaker (1999, $36)$.

${ }^{70}$ Chapter 8 is devoted to a detailed discussion of this.
} 
lematic to combine different intermodal descriptions than it is to combine ones from the same modality.

\subsubsection{Constructionist Primary Meaning: The Case of Malapropisms}

Taken together, there are theoretical considerations that speak in favour of 'ordinary' primary meanings (e.g. in referential terms), while at the same time empirical evidence suggests the contrary. This means: on the one hand, I should incorporate into my theory of meaning the theoretical intuitions that lead to the assumption of primary meaning. On the other hand, however, I should try to avoid doing this by actually postulating reference relations (and related 'meanings'), because the empirical evidence speaks against it. The first thing to do, therefore, seems to be to examine pragmatics and compositionality more closely in order to find out whether there is any other way of accommodating both features. In other words, the task is to do without ordinary primary meanings and, at the same time, to answer the intuitions that give rise to them in the first place. In the case of the semantics/pragmatics distinction, people typically-albeit implicitlyassume that this-omitting primary meaning-is in fact impossible (as the distinction requires lexical word meaning). Regarding compositionality, many theorists take for granted that there are no alternative ways to conceive of compositionality (especially Fodor).

Showing that an alternative approach, which does not involve reference postulates, is achievable amounts to presenting a framework for a new account of meaning. In the next section, I will be discussing particular cases that can't be handled appropriately within classical frameworks. The discussion will be particularly focused on the semantics/pragmatics distinction. Compositionality will be dealt with separately; here I only need to show that compositionality is compatible with my own approach. In order to keep things simple, I stick to the terminology I already introduced above. That is, instead of doing away with 'primary meaning' altogether, I propose a redefinition that is capable of accommodating the empirical results that I have discussed above.

Malapropisms will serve as a starting point for the following discussion. Here is an example of a (German) malapropism: 


\section{(2.1) Wir sollten hier ein Exemplar stationieren. We should here a sample position. \\ 'We should do something as a warning.'}

The classical picture sees the intended meaning as parasitic on the conventional meanings of the expressions used. In comic terms the story goes like this: the hearer of the utterance computes the meaning of the sentence on the basis of the meanings of its parts. This literal interpretation is: 'We should position a sample here', which hardly makes any sense (under normal circumstances). The hearer then figures out that by replacing the phonetically similar "Exempel" for "Exemplar" and "statuieren" for "stationieren", the sentence would make perfect sense. Given certain background assumptions (in particular concerning world knowledge), the hearer, therefore, is able to figure out that 'We should do something as a warning' is the most reasonable interpretation of the sentence. This meaning of the whole sentence is computed from the parts of the sentence (and their possible combinations) exactly as in the case of the first 'try', save for replacing the two 'inappropriate' terms with the 'correct' ones and assuming their primary meanings instead. ${ }^{71}$

The classical source for such inferentialist, neo-Gricean approaches to semantics/pragmatics is Bach \& Harnish (1979). Their framework takes classical primary meaning for granted; the relevant inferences they posit operate on the full content 'literally' conveyed by a given speaker. Thus we read:

We view linguistic communication as an inferential process. The speaker provides, by what he says, a basis for the hearer to infer what the speaker intends to be thereby doing. [...] In general, the inference the hearer makes and takes himself to be intended to make is based [...] on mutual contextual beliefs [...], as we call such salient contextual information. (Bach \& Harnish 1979, 4-5, my emphasis)

The idea here is that whatever language users de facto convey, their conveying something at all is always parasitic on their competency in a lan-

${ }^{71}$ Malapropisms became famous in philosophy of language due to the 'later' Davidson, who discussed them extensively in his A Nice Derangement of Epitaphs (1986). 
guage (i.e. lexical knowledge), their interlocutors' corresponding competency, and their shared beliefs about these competencies. For instance, hearers are said to rely on the so-called 'presumption of literalness', which is

The mutual belief in the linguistic community $C_{L}$ that whenever any member $S$ utters any $e$ in $L$ to any other member $H$, if $S$ could (under the circumstances) be speaking literally, then $S$ is speaking literally. (Bach \& Harnish 1979, 12)

In general, the basis of inferentialist approaches to utterance meaning is always 'literal', i.e. context-independently specifiable sentence meaning.

First evidence supporting the claim that there must be an alternative way of how we arrive at the meaning of an utterance without the detour via reference postulates comes from the observation that the procedure just described is simply not applicable across the board. There are cases of successful human communication that do not seem to operate on sentential meaning. This suffices to establish the claim that there must be an alternative route. To begin with, the example above is somewhere in the middle on a continuum of cases to which the classical picture is more or less applicable. For example, the obvious inappropriateness of "Exemplar" could trigger the relevant inferences. Irony is another very good example of cases where one could easily get the impression that the classical picture gets at least something right. This is because the intended reading of an ironic utterance is the 'opposite' of the literal meaning. In the "Exemplar" example, the strategy seems still quite plausible, because world knowledge can be exploited in finding out that "Exemplar" is used inappropriately here, which, in conjunction with the phonetic similarity of "Exemplar" and "Exempel", might cause the hearer to conclude that the speaker mixed up the two. So the gist is this: there are cases (e.g. irony) in which inferentialist strategies work quite well and others (e.g. a slip of the tongue) in which they work fairly well. Accordingly, the most interesting cases are those in which people are able to determine utterance meaning without accessing the alleged literal sentence meaning. ${ }^{72}$

${ }^{72}$ This is an area of research in which people seek answers on the basis of empirical data. Typically, the underlying idea here is that shorter reaction times for specific interpretations of sentences (e.g. Recanati's minimal proposition) indicate that language users 
To see what is actually happening, it will help to look at examples in which the goings-on are not obscured by contingencies like phonetic similarity. That is, examples which resemble malapropism, irony, etc. in that their pragmatic meaning is recognisable; but in which that fact can't be explained in terms of primary meaning. The idea here is: if recognition of pragmatic meaning can be explained sufficiently for these cases, the same strategy-which by assumption must be a strategy that does not recur to primary meaning-might be similarly applicable to other cases. The following example will serve as a starting point for the discussion:

$$
\begin{aligned}
& \text { Das Wetter ist heute aber usellig. } \\
& \text { The weather is today however cold. } \\
& \text { 'It is cold today'. }
\end{aligned}
$$

The peculiarity here is the word "usellig", which is unknown in Standard German (unknown, at least, beyond the borders of the Ruhr area). In a context in which speaker and hearer are debating the weather, and in which it is obvious to both of them that the weather is bad (and obvious that this is obvious to the respective other, etc.), an otherwise competent speaker of German is able to recognise the meaning of "usellig" in this specific conversational context. Of course, this is partly due to the fact that the hearer understands "Das Wetter ist heute aber__." But the relevant point here is that, by assumption, "usellig" (and hence the whole utterance) can't be understood by the hearer on the basis of its primary meaning (for this would require this meaning to be known in advance).

Following Horwich here, to understand a word is to implicitly know its use. Understanding in actual communication situations has, trivially, two aspects: the hearer's and the speaker's perspective. From the hearer's point of view, understanding lies in the ability to recognise the speaker's use of a given term in a given context (e.g. to recognise that "usellig" means 'cold', 'unpleasant', 'misty'). It is the speaker's 'responsibility' to enable such understanding-e.g. by taking into account what is common ground between them. Which sources, so to speak, enable the hearer to understand

\footnotetext{
'access' these interpretations more directly-vice versa for longer reaction times. For some (more or less) recent research in this area, see Nicolle \& Clark (1999) and Noveck $\&$ Reboul (2008).
} 
a given utterance is secondary from the theoretician's perspective, as long as understanding can be established. In the malapropism case, it is possible to give an inferentialist explanation for how understanding is established (due to phonetic similarities). In the "usellig" example, this possibility is no longer given, since "usellig" is unknown to the hearer and shares no commonalities with familiar words. ${ }^{73}$ Which is to say: if there were any inferential processes involved (in order to arrive at the intended interpretation), these are not processes operating on "usellig". What the Tomasellian programme, quite plausibly, suggests here is that a hearer is able to understand the utterance in question because the involved interlocutors engage in a cooperative activity (e.g. informing the other about one's impression regarding the weather outside).

So even if certain classes of linguistic effects-like malapropisms-can be explained in terms of primary meaning, namely by recognising the inappropriateness of the term actually uttered, there remain other cases for which such an explanation is unavailable. This, in turn, might be interpreted as indirect evidence against primary meaning even in the former cases. Because the latter kind of explanation-which, to be sure, is up to now only a sketch of an explanation-is equally applicable to malapropisms and the like. This is an issue I will return to in 8.3. In the present context, let me just note that if one tries to explain malapropisms (and similar effects) without ordinary primary meaning, the relevance of cues such as phonetic similarities does not vanish. In other words, the inferential processes that lead from, say, "Konifere" to "Koryphäe" must and can be kept in a modified framework. The upshot is this: there seem to be cases in which hearers know what a speaker meant, although they do not primarily rely on primary meaning, i.e. on what is literally said. In fact, in these cases pragmatic meaning seems to be retrievable without any prior knowledge of the primary meaning of relevant constituents. A satisfying theory of meaning has to accommodate this result.

Thus far I have really only hinted at a solution to the problem of how hearers achieve understanding in cases where they can't rely on their prior semantic knowledge. A more detailed picture will emerge in the course of

${ }^{73}$ Save for the hearer's syntactic bootstrapping capacities (Gleitman 1990). For example, the ending "-ig" signals that "usellig" might be an adjective. 
this book. The purpose of the present chapter, rather, is to present a range of examples that question the status of primary meaning in semantic theory. The above discussion was focused on primary meaning in general. However, primary meaning in terms of reference/satisfaction is specifically relevant for varieties of truth-conditional approaches to semantics; they require reference, whereas usage-based theories contingently employ referential terms. This severely limits TCS's explanatory resources. A very illustrative case at hand in this regard is language acquisition, an issue to which I shall turn now.

\subsubsection{Constructionist Language Acquisition}

Language acquisition is a difficult issue for Davidsonian and neo-Davidsonian approaches, since these frameworks are first and foremost theories that are specifically designed to handle competencies of fluent natural language speakers. Remember, one major motivation for Davidson is the problem of explaining productivity, which, in his view, can only be solved by assuming that people master recursively defined rules that compute sentence meaning from given atomic meanings of the relevant constituents. This explanation, however, concerns what people allegedly know now. It is blind as to how they learnt to 'associate' word forms with meaning. For example, it is silent on the obviously learnt ability of human communicators to associate "bank" with either 'riverbank' or 'financial institution'. There are many problematic aspects in this context that TCS faces, one of which is that the relevant base clauses (e.g. that "snow" refers to snow) are either known or unknown. Spelling out semantic knowledge in terms of knowledge of reference relations does not allow for intermediate steps in the ontogeny of semantic abilities (i.e. degrees of knowledge).

Emma Borg, in a recent attempt to defend neo-Davidsonian semantics, ${ }^{74}$ addresses the problem of learnability very briefly. She says: word learning seems to be intimately bound to one's mindreading ability, i.e. one's ability to recognise others' mental states, in particular intentions (Borg 2004b). This, it seems, contradicts her own theoretical framework insofar as she assumes that semantic competence is completely disentangled from inten-

${ }^{74}$ Her most relevant works include: Borg (2004b, 2004a, 2012a, 2012b). 
tions and the speaker's or hearer's ability to ascribe or recognise them. But, she claims, this apparent conflict may be solved thus:

Any appeal to intentionality as a fundamental element in acquiring a lexicon is, I believe, compatible with a modular theory of linguistic (and specifically semantic) understanding which claims that appeal to speaker intentions is not necessary in order to grasp literal linguistic meaning. This is because the conditions necessary to set up the linguistic system in the first place need not be the same as the conditions subsequently required to be in place for the proper functioning of that system after it has been set up. Even if we ultimately decide that language acquisition is an essentially inferential process requiring sensitivity to speaker intentions, there is no direct move from this idea to the claim that linguistic understanding per se is such an inferential process, appealing to such a sensitivity. (Borg 2004b, 139, emphasis original)

The crucial step here is the claim that 'there is no direct move from this idea [language acquisition requires usage-based explanation] to the claim that linguistic understanding per se is such an inferential process'. Trivially, that is true in the sense that the concession concerning language acquisition does not imply TCS's falsity. However, it does reveal that there is a huge explanatory gap, which is not easy to bridge.

In the quoted passage, Borg concedes that some plausible current theories of word learning make usage-based assumptions. ${ }^{75}$ Although, in fact, there is no 'direct move' from this concession to a usage-based theory of meaning (in contrast to, for example, a usage-based theory of word learning), it places the burden of proof on the formal semanticist's or minimalist's side. Two reasons are especially relevant in this context. Firstly, if usage-based explanations are already required for language acquisition,

${ }^{75}$ More precisely, she talks about intention-reading capacities and hearers' inferential processes operating on those capacities. I think it is legitimate to call the approaches that she summarises here 'usage-based', as the philosophically relevant point is that children associate a given word with a particular meaning only due to the acquaintance with that word type in specific contexts of utterance. See, for example, Borg's quotations from Bloom (2000). 
there must be really good reasons to give an alternative, potentially contradictory explanation for 'linguistic understanding per se'. Secondly, without further support there is absolutely no reason to think that suddenly-in the blink of an eye-understanding develops from being based on mindreading capacities to being based on knowledge of reference relations.

Here is one small argument in support of the last claim. Suppose that Borg is right in assuming a fundamental distinction between understanding in language acquisition and understanding per se. Then there are two possibilities for diachronic meaning shifts. One is that meaning shifts involve abilities different from mindreading capacities; which is absurd, for that would further complicate the picture. Or meaning shifts rely on the very same abilities that are employed in language acquisition (e.g. mindreading); which is also implausible, for in this case the minimalist explanation of 'linguistic understanding per se' would become even more superfluous. Either way, one quite severe problem with Borg's picture seems to be the idea that word learning lies in recognising which word forms belong to which referents-lexical knowledge which is fixed, once it is learnt.

More generally, the problem seems to be Borg's deep conviction that semantics is an area of study that is ultimately disentangled from the study of communication and utterance comprehension. ${ }^{76}$ She acknowledges without much hesitation that utterance comprehension clearly involves pragmatic processes. As just seen, she even goes as far as to acknowledge that language acquisition recurs to essentially the same mechanisms that are relevant for utterance comprehension in general. Here, I think, Borg underestimates the scope of her 'no direct move' claim. The problem is that, in effect, her thesis is this: understanding in word learning contexts involves only pragmatic processes; but once word meaning is learnt, the very same processes are not sufficient any more for understanding. This is implausible, if anything is. Let me elaborate a bit. For conceptual reasons, language acquisition must be possible without semantic knowledge regarding the words the acquisition process is concerned with. (Otherwise it is not word learning.) Crucially, Borg-rightly, I think-assumes that the acquisition of lexical knowledge depends on one's ability to comprehend utterances in which the relevant word occurs (cf. her short review of Bloom's

${ }^{76}$ See especially the second chapter of her 2004 book and her 2012 book, respectively. 
experiment; Borg (2004b, 136-138)). Taken as a whole, this amounts to saying that the areas of language learning and language application essentially require usage-based explanations; but what is learnt (i.e. what constitutes understanding) is not (knowledge of) use but (knowledge of) usage-independent reference relations.

It is important at this point to remember that usage-based theories do not deny that competent speakers rely on lexical knowledge. Horwich, for example, would be perfectly happy to acknowledge that the meaning of "snow", for example, depends on snow (e.g. due to the frequency with which people use the word "snow" in the presence of snow). $\mathrm{He}$ would even claim that his theory is able to explain, in usage-based terms though, why and how "snow" refers to snow. The point here is that lexical knowledge-knowledge concerning stable word meaning-is a central ingredient of mainstream usage-based theories. Bearing this in mind, Borg's conviction that usage-based explanations are required for language acquisition and communication but that nevertheless lexical knowledge is usage-independent looks even more implausible. ${ }^{77}$ The underlying problem is that evidence in favour of Borg's conclusion that is based solely on the observation that human behaviour is specifically guided by lexical knowledge is unavailable, as the rival theory (usage-based semantics) posits lexical knowledge too. The only remaining option that I see here is to argue that the explanation of lexical knowledge itself fares better in truthconditional terms than in usage-based terms. I do not see this. On the contrary, there is good reason to assume the opposite: if language acquisition and communication require usage-based explanations-as the minimalist acknowledges-and lexical semantics can be accounted for in terms of use as well, then the by far most elegant explanation is based on the assumption that lexical knowledge lies in implicit knowledge of use.

\footnotetext{
${ }^{77}$ To be sure, talking about 'usage-independent' here is a bit tricky. Borg certainly does not want to say that what terms actually mean is independent from use (after all, use determines that "bank" means either 'riverbank' or 'financial institution'). Furthermore, she certainly also does not want to say that lexical knowledge as such is use-independent (e.g. acquiring lexical knowledge involves mindreading capabilities). Rather, her claim is that the lexical knowledge people have, once they acquired it, is use-independent in the sense that they know something about the meaning of a given term, independently of how it is applied in specific communication situations (e.g. the knowledge that "snow" refers to snow).
} 
A related worry in the context of language acquisition is that neo-Davidsonians who acknowledge that acquiring lexical knowledge is facilitated by utterance comprehension face the following difficulty. Toddlers are able to comprehend whole utterances, but they do so by treating them (first) as unanalysable units. This phenomenon is usually labelled 'holophrase' or 'frozen phrase'. The basic idea here is that although toddlers can understand and apply these phrases in accordance with their interlocutors' use, they do not see the underlying (lexical and syntactic) structure of these phrases. From a philosophical point of view, the problem here is that this obviously undermines Davidson's conviction that the human ability to understand well-formed complexes is tightly linked with one's prior knowledge of recursive rules. Tomasello (2003a) summarises his view as follows:

[...] children's early one-word utterances may be thought as 'holophrases' that convey a holistic, undifferentiated communicative intention, most often the same communicative intention as that of the adult expressions from which they were learnt [...]. [In the case of frozen phrases] there is different syntactic work to do if the child is to extract productive linguistic elements that can be used appropriately in other utterances, in other linguistic contexts, in the future. For this the child must engage in a process of segmentation, with regard not only to the speech stream but also to the communicative intention involved-so as to determine which components of the speech stream go with which components of the underlying communicative intention. (36 and 38 , all emphases mine)

Such a view is perfectly compatible with what Borg, for example, says about word learning, i.e. that it crucially involves being capable of reading minds. However, this is incompatible with the Davidsonian ideas in at least two respects. Firstly, it undermines Davidson's view that language comprehension proceeds from the bottom up, so to speak. Rather, in the view advocated by Tomasello, language comprehension is primarily a topdown process, i.e. children first understand utterances in context and then begin to deconstruct utterance meaning into its (context-independent) lexical and syntactic constituents. Secondly, Tomasello's remarks on holophrases and frozen phrases also question the idea that the result of such 
abstraction processes might be anything like (knowledge of) the Tarskian base clauses that, Davidson thinks, underlie adults' cognitive abilities. To summarise, language acquisition is, in several respects, highly problematic for Davidson and his disciples. The fundamental issue is that, with conceptual necessity, language acquisition (as opposed to language application) requires that structures (i.e. constructions at several levels of description, especially words and syntactic structures) are learnt on the basis of a prior understanding of the complexes that are built according to those structures. That is to say, language acquisition must primarily be explained in terms of abstraction. But if Davidson's story about utterance comprehension fails in the case of the acquisition process, then there is no reason to assume it will fare any better in the 'ordinary' cases of regular language use. 